\title{
Influence of Electrolyte Impurities from E-Waste Electrorefining on Copper Extraction Recovery
}

\author{
Jovana Djokić $^{1, *(\mathbb{C})}$, Dragana Radovanović ${ }^{2}$, Zlatko Nikolovski ${ }^{3}$, , Zoran Andjić $^{1}\left(\mathbb{D}\right.$ and Željko Kamberović $^{4}$ \\ 1 Innovation Centre of Faculty of Chemistry in Belgrade Ltd., University of Belgrade, Studentski Trg 12-16, \\ 11000 Belgrade, Serbia; zoranandjic@yahoo.com \\ 2 Innovation Centre of Faculty of Technology and Metallurgy in Belgrade Ltd., University of Belgrade, \\ Karnegijeva 4, 11000 Belgrade, Serbia; divsic@tmf.bg.ac.rs \\ 3 Institute Mol, Nikole Tesle 15, 22300 Stara Pazova, Serbia; zlatko_nbg37@hotmail.com \\ 4 Faculty of Technology and Metallurgy, University of Belgrade, Karnegijeva 4, 11000 Belgrade, Serbia; \\ kamber@tmf.bg.ac.rs \\ * Correspondence: djokic@chem.bg.ac.rs
}

Citation: Djokić, J.; Radovanović, D.;

Nikolovski, Z.; Andjić, Z.;

Kamberović, Ž. Influence of

Electrolyte Impurities from E-Waste Electrorefining on Copper Extraction Recovery. Metals 2021, 11, 1383.

https://doi.org/10.3390/

met11091383

Academic Editor: Alexandre Chagnes

Received: 30 July 2021

Accepted: 25 August 2021

Published: 31 August 2021

Publisher's Note: MDPI stays neutral with regard to jurisdictional claims in published maps and institutional affiliations.

Copyright: (c) 2021 by the authors. Licensee MDPI, Basel, Switzerland. This article is an open access article distributed under the terms and conditions of the Creative Commons Attribution (CC BY) license (https:/ / creativecommons.org/licenses/by/ $4.0 /)$.

\begin{abstract}
In order to reflect possible issues in future sole e-waste processing, an electrolyte of complex chemical composition reflecting system of sole e-waste processing was obtained by following a specially designed pyro-electrometallurgical method. The obtained non-standard electrolyte was further used for the purpose of comprehensive metal interference evaluation on the copper solvent extraction (SX) process. Optimization of the process included a variation of several process parameters, allowing determination of the effect of the most abundant and potentially the most influential impurities (Ni, Sn, Fe, and Zn) and 14 other trace elements. Moreover, comparing three commercial extractants of different active chelating groups, it was determined that branched aldoxime reagent is favorable for $\mathrm{Cu}$ extraction from the chemically complex system, as can be expected in future e-waste recycling. The results of this study showed that, under optimal conditions of $20 \mathrm{vol} . \%$ extractant concentration, feed $\mathrm{pH} 1.5, \mathrm{O} / \mathrm{A}$ ratio 3, and 10-min phase contact time, $88.1 \%$ of one stage $\mathrm{Cu}$ extraction was achieved. Co-extraction of the $\mathrm{Fe}, \mathrm{Zn}, \mathrm{Ni}$, and $\mathrm{Sn}$ was under $8 \%$, while $\mathrm{Pb}$ and trace elements were negligible. Optimal conditions $\left(\mathrm{H}_{2} \mathrm{SO}_{4} 180 \mathrm{~g} / \mathrm{L}, \mathrm{O} / \mathrm{A}=2\right.$, and contact time $5 \mathrm{~min}$ ) enabled $95.3 \% \mathrm{Cu}$ stripping and under $6 \%$ of the most influential impurities. In addition, an impurity monitoring and distribution methodology enabled a better understanding and design of the process for the more efficient valorization of metals from e-waste.
\end{abstract}

Keywords: e-waste; electrolyte recycling; solvent extraction; chelating extractants; copper; impurities influence; metal distribution

\section{Highlights:}

- Electrolyte of highly complex chemical composition resulting from specially designed pyro-electrometallurgical e-waste process, aiming to reflect future obstacles considering sole e-waste recycling

- A one-factor solvent extraction methodology for the comparison of three commercial extractants in terms of efficiency, distribution coefficients, selectivity, and influence of impurities on $\mathrm{Cu}$ extraction from experimentally obtained electrolyte

- $\quad$ Feed pH, extractant, and stripping agent concentration affect solvent extraction most significantly through reaction equilibrium shifts and active centers availability

- Optimized process conditions enable selective $\mathrm{Cu}$ extraction among highly abundant $\mathrm{Fe}, \mathrm{Zn}, \mathrm{Pb}, \mathrm{Ni}$, and $\mathrm{Sn}$ and trace elements (i.e., $\mathrm{Al}, \mathrm{Co}, \mathrm{Cr}, \mathrm{Mg}, \mathrm{Na}, \mathrm{Sb}, \mathrm{Ga}, \mathrm{Ge}$ )

- Transfer monitoring, distribution, and methodology for additional valorization of metals 


\section{Introduction}

Resource shortage, environmental and human health issues, and economic incentives have promoted recycling to become mandatory in the modern world. Efforts to reduce natural exploitation, preserve the environment, and promote the reuse and valorization of previously discarded materials, thereby minimizing process waste, have become one of the most important goals. This approach leads to closing up the material flow loop and achieving a circular economy [1]. The same concept is applied to electrical and electronic waste (e-waste) also. As the waste stream increases at an ever-growing rate, recycling has become of great concern in recent decades. In terms of metal content, printed circuit boards (PCB) are the most valuable part of e-waste, containing more than 60 elements of the periodic table, from $28 \%$ [2] to $40 \%$ [3] of metals, including base and precious metals, rare, scarce elements, but also hazardous, toxic, metals. Besides metals, this material contains various organic compounds. This extremely heterogeneous composition as well as chemical complexity represent the main obstacle for efficient valorization, making e-waste and PCB recycling quite challenging [4]. At the same time, metal value makes it a major secondary resource and an attractive material for recycling [5]. Considering the abundance of copper and precious metals in e-waste, which is higher than in ore deposits [6], the usual valorization methods are analogous to those in primary metal production, built on pyro-electro and/or hydrometallurgical bases [7]. The application and significance of the electrometallurgical approach in the production of metals from solution are given in a detailed review by Rai et al., emphasizing that there are limitations in e-waste processing due to the complexity of the material itself [8].

If the pyrometallurgical route (PM) is employed, the smelting feed is usually a synergetic mixture of ore concentrate and other valuable scrap materials. Several plants for smelting and refinery, such as Umicore [9], Boliden [10], and Naoshima (Mitsubishi Materials Corporation) [11], have integrated e-waste in processing, accounting for $15-30 \mathrm{wt} . \%$ of the feed. Yet, considering the rising trend of e-waste, it is inevitable that a mass fraction of this material in the feed will also grow. So, if smelting feed is predominantly or solely e-waste, it is expected to negatively affect the traditional production process due to inlet deviating in terms of compounds and concentration. Due to similar physical-chemical properties, selective separation of metals between smelting phases is hindered [12]. In general, obtained blister copper is further refined through an anode oxidation process to decrease the abundance of the impurities, such as $\mathrm{Al}, \mathrm{Ba}, \mathrm{Be}, \mathrm{Ca}, \mathrm{Cr}, \mathrm{Fe}, \mathrm{Mg}, \mathrm{Mn}, \mathrm{Na}$, and $\mathrm{Zn}$. At the same time, precious metals, as well as $\mathrm{Bi}, \mathrm{Pb}, \mathrm{Ni}, \mathrm{Cd}, \mathrm{Sb}$, and $\mathrm{Sn}$, remain in molten blister copper [13]. Further, the PM route is followed by electrochemical deposition where, besides cathode $\mathrm{Cu}$, electrolyte and anode slime are generated as by-products [14]. If feed material is sole e-waste, a non-standard tin precipitate is also generated during electrorafination (ER) due to a high Sn concentration in the starting material. This non-standard by-product requires additional treatment steps [15]. Due to upstream recycling chemistry and complex electrolyte composition, the subsequent electrowinning (EW) step is also challenging. Besides $\mathrm{Ni}, \mathrm{Co}, \mathrm{As}$, and $\mathrm{Sb}$, the main obstacle for $\mathrm{EW}$ is Fe content [16], whose concentration above $1 \mathrm{~g} / \mathrm{L}$ causes current efficiency losses due to Fe cathode reduction as a competitor reaction, resulting in low cathode deposition of $\mathrm{Cu}$ with poor quality [17].

Likewise, in the case of pyro-electro, in a hydrometallurgical route, where leaching by various lixiviants can be conducted directly on target e-waste components or take place after smelting, EW is an established metal separation method [18]. Moreover, the hydrometallurgical route is a prospective alternative to pyrometallurgical processing, especially for small and medium-sized enterprises [19]. Yet again, with all upstream recycling chemistry issues inherent, another issue is the buildup of metal impurities in the cyclic treatment set-up, where impurities severely impact the EW process [20].

Accordingly, no matter which route is chosen, efficiency and selectivity are low due to the material composition complexity mentioned earlier. Besides target elements, usually $\mathrm{Cu}$, the obtained electrolyte or leaching solution contains simultaneously dissolved elements that are considered impurities, negatively affecting the recycling process. 
The incorporation of e-waste into established metal production routes is challenging as e-waste composition constantly changes. Even more challenging is how to effectively process this feed material with additional value without prior dilution by primary and other scrap materials, in response to today's circular economy demands [21].

Therefore, in order to achieve selective metal valorization and obtain high-purity products, generated solutions require downstream purification and concentration processes. Besides the aforementioned EW, other purification/concentration methods include solvent extraction, ion exchange, precipitation, and their combinations [22,23]. A choice depends on the lixiviant nature, target metal concentration, effect of impurities, and process economics [24]. Among them, solvent extraction is an established $\mathrm{Cu}$ purification technique commonly applied in industry and small-scale operations [25].

Solvent extraction (SX) is a traditional separation method that has been used for decades in hydrometallurgy of primary metal production for the purpos of separation, purification and concentration of metals in the solution. Now, the goal is to assimilate this technology into e-waste recycling. SX is characterized by easy operation, low capital and economic costs, and flexibility [26]. The latter is very important considering the chemical composition diversity of e-waste when rigid treatment methods can hardly follow composition fluctuation. Extractants for SX are under constant development and improvements to ensure selectivity, increase extraction efficiency, and facilitate re-extraction. Several extraction types and mixtures, with or without modifiers, have been used to extract $\mathrm{Cu}$, including hydroxyoximes, hydroxy benzophenone oximes, aldoxime, quinolines, organic acids, and organophosphorus based compounds [27]. As e-waste recycling solutions are non-standard and burdened by various elements, the efficiency of different extraction agents has been studied. Due to low selectivity, many have found that removing metal impurities, especially Fe, is necessary before SX [28,29], meaning an additional technological step is required, representing a new point of metal values loss.

In this study, aldoxime and ketoxime/aldoxime blend with or without modifier were used to determine selectivity and efficiency in metal separation. Accordingly, the results of the literature survey data are presented as follows. It is reported that Acorga ${ }^{\circledR}$ aldoxime reagents exhibit high selectivity and recovery toward $\mathrm{Cu}$ even when the concentration of Fe is predominant in the solution [30]. By optimizing the solvent extraction conditions (feed $\mathrm{pH} 1.1, \mathrm{M} 564016 \mathrm{vol} \%$, O/ A = 1, contact time $3 \mathrm{~min}$ ), the efficiency of copper extraction from the e-waste sulfate leaching solution was more than $85 \%$. It is also concluded that the presence of iron negatively affected $\mathrm{Cu}$ extraction efficiency and that the strength of $\mathrm{H}_{2} \mathrm{SO}_{4}(254 \mathrm{~g} / \mathrm{L}$ as the optimal one), as the stripping agent, highly influences Fe stripping percentage [3]. Deep [31] and Ferreira [32] used Acorga ${ }^{\circledR}$ M5640 modified by isotridecanol to selectively extract $\mathrm{Cu}$ from a sulfate solution dominated by Fe and $\mathrm{Zn}$ and found that the modifier hindered $\mathrm{Cu}$ loading but facilitated stripping. The results considering Fe co-extraction deviate, but the percentages are undoubtedly low and influenced by the $\mathrm{pH}$ of the feed solution. Ochromowicz and Chmielewski compared commercial LIX ${ }^{\circledR}$ reagents (984N and 612N-LV) with the Acorga ${ }^{\circledR}$ M5640 for the Cu extraction in the presence of the equal Fe concentration (both about $30 \mathrm{~g} / \mathrm{L}$ ). The latter extractant proved to be more efficient, yet it was determined that Fe co-extraction is highly influenced by feed $\mathrm{pH}$ and extractant concentration. Optimal process conditions were M5640 30 vol.\%, and $0.75 \mathrm{pH}$ [26]. Linden et al. came to a similar conclusion in their study. They determined that, even with a low metal concentration $(\mathrm{Cu}, \mathrm{Fe}, \mathrm{Cr}, \mathrm{Zn}, \mathrm{Pb}, \mathrm{Ca}$, and $\mathrm{Ni}$, each of $500 \mathrm{ppm})$, co-extraction of Fe from synthetic feed could reach almost $40 \%$ and $12 \%$ by using LIX $^{\circledR}$ $984 \mathrm{~N}$ and Acorga ${ }^{\circledR}$ M5640, respectively [33]. Even if $\mathrm{Cu}$ is predominant in the solution, selectivity is not achieved, neither by LIX $^{\circledR}$ series or Acorga ${ }^{\circledR}$ OPT, which is extractant modified to facilitate extraction and stripping [34], and Fe co-extraction is challenging to avoid [35]. On the contrary, Banza concluded that LIX ${ }^{\circledR} 984 \mathrm{~N}$ proves to be $\mathrm{Cu} / \mathrm{Fe}$ selective if $\mathrm{pH}$ is above 2.5 [36]. Yet, the precipitation of Fe during $\mathrm{Cu}$ extraction at the mentioned $\mathrm{pH}$ was not discussed. 
The aforementioned discussion showed quite extensive research on copper SX. When it comes to the influence of metal on the process efficiency, the focus is usually on Fe, with less attention paid to the interference of other metals. Having in mind the traditional circuit set-up as a coupled hydro-electro treatment, the buildup of impurities in specific phases of the process stages is unavoidable.

According to the literature review, recycling is based on an e-waste dilution methodology in primary pyro-processing feed. Moreover, published studies considering solution purification of e-waste processing mainly address the issue of the influence of base metals on $\mathrm{Cu}$ extraction in simplified systems.

This paper addresses the knowledge gap of sole e-waste processing and the comprehensive determination of impurities interferences. Hence, at the core of this study was the aim to determine the effect of the most abundant and potentially the most influential impurities $(\mathrm{Ni}, \mathrm{Sn}, \mathrm{Fe}$, and $\mathrm{Zn}$, of which $\mathrm{Ni}$ and $\mathrm{Sn}$ are the most challenging since they cannot be removed by pyro-processing) as well as 14 other trace elements (i.e., $\mathrm{Al}$, $\mathrm{Bi}, \mathrm{Ca}, \mathrm{Co}, \mathrm{Mg}, \mathrm{Na}, \mathrm{Sb}, \mathrm{Ga}$, etc.) on copper SX. In addition, metal distribution through electro-hydrometallurgical e-waste processing was determined in order to understand interferences in a chemically complex system.

For that purpose, various e-waste categories as feed material have been intentionally selected to provide the generation of an electrolyte of non-standard chemical composition, further used as feed for SX optimization. The effect of extractant concentration, aqueous to liquid ratios, phase contact time, and feed $\mathrm{pH}$ was determined and compared for each of the three investigated extractants. Stripping optimization also included one-factor parameters variations. According to extraction/stripping efficiency and co-extraction levels, proper SX conditions and metal distributions were defined. These approaches allow to understand future obstacles in the processing of sole e-waste and contribute to the design of a process that will enable an efficient flow of materials.

\section{Experimental}

2.1. Material

A total of $400 \mathrm{~kg}$ of various e-waste categories, which consisted of $60 \mathrm{wt} . \%$ metallic fractions granulate, 35 wt. $\%$ waste PCBs fraction, of which 5 wt. \% were RAM cards, and 5 wt. \% CPU fractions, were received from local suppliers. E-waste fractions, all but metallic granulate, went through the preparation step.

\subsection{Sole E-Waste Preparation Process}

The vacuum pyrolysis depolymerization method was conducted on PCBs and CPUs fractions of received e-waste. Organic compounds that were removed by this step (8.9 wt.\% of gases and $17.5 \mathrm{wt}$ \% of liquids) would have otherwise jeopardized further processing.

The depolymerized sample (30 wt.\%), altogether with metallic granulate (65 wt.\%) and flux material (slag, $5 \mathrm{wt} . \%$ ), was the feed for reducing smelting in a DC electric arc furnace. Besides slag and filter dust, the main smelting product was metal phase as non-standard $\mathrm{Cu}$ alloy weighing $75 \%$ by weight of the feed, and this was used for anode casting. The traditional step of anode oxidative refining was excluded with the intention of preserving a high content of $\mathrm{Fe}, \mathrm{Zn}, \mathrm{Na}, \mathrm{Cr}, \mathrm{Mn}, \mathrm{Ti}, \mathrm{Al}, \mathrm{Ba}, \mathrm{Be}, \mathrm{Mg}$, and $\mathrm{Ca}$ in the cast anodes, which would otherwise be mostly removed from the molten copper. This approach makes it possible to obtain a particularly non-standard complex electrolyte, which was the intention for this study. Each casted anode weighted between 23 and $24 \mathrm{~kg}$, and 4 anodes, with a total mass of $92.4 \mathrm{~kg}$, were used in the next step, electrorefining (ER). The ER products were cathode copper ( $85 \mathrm{~kg}$ of $99.83 \%$ purity), as the main standard product, anode slime, and electrolyte as standard by-products (13 kg and $200 \mathrm{~L}$, respectively) and tin precipitate as a non-standard by-product ( $4 \mathrm{~kg}$ of fine suspended particles periodically extracted by coagulation from electrolyte during ER).

Depolymerisation, smelting, ER, and tin precipitate extraction processes are described by Djokić et al. [15]. 
All experimentally obtained products and by-products were analyzed, while the electrolyte of complex chemical composition was used as the aqueous phase (feed) for solvent extraction optimization and for monitoring the distribution of impurities.

\subsection{Reagents and Procedure}

Three extractants were used in the current study: Acorga ${ }^{\circledR}$ series M5640 (branched, C9 modified aldoxime reagent with active 5-nonyl-2-hydroxy-benzaldoxime), OPT 5510 (C9 ester modified aldoxime-ketoxime reagent), and LIX ${ }^{\circledR}$ series $984 \mathrm{~N}$ reagent (nonmodified aldoxime-ketoxime blend containing 5-nonylsalicylaldoxime and 2-hydroxy5-nonylacetophenone oxime). Extractants were not additionally purified. Other used chemicals were p.a. grade.

The organic phase (OP) was prepared by diluting extraction agents in kerosene to achieve desired concentrations. This diluent was selected based on its physical-chemical properties (i.e., hydrophobic, low dielectric constant favorable for cation extraction because it does not promote the polymerization of chelating extractants over hydrogen bridges), proper safety, health, and environmental characteristics, and applicability in industry.

The solvent extraction (SX) experiments were carried out by varying extractant concentration in the organic phase (M5640, 5-30 vol.\%), organic to aqueous phase (O/A) ratio (1/3, $1 / 2,1 / 1,2 / 1,3 / 1$, and $4 / 1)$, contact time $(2.5,5,7.5,10,12.5$, and $15 \mathrm{~min})$, and $\mathrm{pH}$ of feed solution $(0,1,1.5$, and 2$)$. $\mathrm{NaOH}$ (Fisher Chemical) was used for $\mathrm{pH}$ adjustment by adding the appropriate amount to the electrolyte until the desired $\mathrm{pH}$ was reached. Experiments were conducted in separating funnels at room temperature by contacting corresponding volumes of aqueous and organic phases. After complete phase disengagement, which required 3-5 min, raffinate was sampled for analysis, and the loaded organic phase was further used for stripping. This step optimization included a variation of stripping agent concentration $\left(\mathrm{H}_{2} \mathrm{SO}_{4}\right.$ (Carlo Erba reagents), 100-200 g/L), O/A ratio (1/2, 1, 2, and 4), and contact time (2.5 to $15 \mathrm{~min}$ ). Appropriate volumes of phases are contacted for desired time. After separation by gravitation, analysis of aqueous phases (raffinate and loaded strip) followed.

In the subsequent experimental set, the extraction behavior of metals using LIX ${ }^{\circledR} 984 \mathrm{~N}$ and OPT 5510 was investigated under experimentally determined optimal parameters for the M5640 extractant. All experiments were conducted as one-stage extraction/stripping.

Determined parameters were used to define optimal process conditions for SX which takes place according to Equation (1), [26]:

$$
\mathrm{M}^{\mathrm{n}+}+\mathrm{nHA}=\mathrm{MA}_{\mathrm{n}}+\mathrm{nH}^{+}
$$

where $\mathrm{M}^{\mathrm{n}+}$ is a metal cation and HA is an extractant.

This process is reversible, and according to stoichiometry, for each mole of extracted metal ion, it is expected to increase raffinate acidity (i.e., one mol of divalent metal ion generates two moles of $\mathrm{H}^{+}$), which shifts the equilibrium towards a stripping reaction.

\subsection{Analytical Methods}

The chemical characterization of casted anodes was determined by analysis of the elemental composition (Elementar ${ }^{\mathrm{TM}}$ Vario EL III, CHNS/O elemental analyzer), X-ray fluorescence spectrometry (XRF, Thermo Scientific Niton ${ }^{\mathrm{TM}}$ XL3t, calibrated to operate in alloy mode), and optical emission spectrometry (OES, SPECTROMAX $\mathrm{x}^{\mathrm{TM}}$ arc/spark, calibrated for $\mathrm{Cu}$ alloy composition determination). A representative sample of casted anodes was digested in $\mathrm{HNO}_{3} / \mathrm{HF}\left(3 / 1\right.$ volume ratio, $15 \mathrm{~min}$ at $\left.180^{\circ} \mathrm{C}\right)$ mixture to perform a more comprehensive analysis. The chemical composition of all obtained solutions was determined via the inductively coupled plasma method with an optical emission spectrometer (ICP-OES, SPECTROBLUE ${ }^{\mathrm{TM}}$ TI, Smart Analyzer Vision data processing software, in relation to the AccuStandard ${ }^{\circledR}$ analytical reference standards). Measurements of $\mathrm{pH}$ were conducted by using an INO-LAB ${ }^{\circledR}$ pH-720 $\mathrm{pH}$ meter, calibrated by LLG $^{\mathrm{TM}}$ buffer solutions to operate in acid environment. 
The concentrations of metals in aqueous phases were determined by direct instrumental analysis as triplicates, including the standard deviation of the measurements and the calibration of the instrument, while mass balance calculations determined the concentrations of metals in the loaded organic phases. Parameters such as the distribution coefficient (D), the extraction/stripping efficiency ( $\% \mathrm{E}$ and $\% \mathrm{~S}$, respectively), and the separation factor $\left(\beta_{\mathrm{A} / \mathrm{B}}\right)$ were calculated for each experiment according to Equations (2)-(5).

$$
\begin{gathered}
\mathrm{D}=\left([\mathrm{M}]_{0}-[\mathrm{M}]_{\mathrm{aq}}\right) /[\mathrm{M}]_{\mathrm{aq}} \\
\% \mathrm{E}=\left(\mathrm{D} /\left(\mathrm{D}+\left(\mathrm{V}_{\mathrm{aq}} / \mathrm{V}_{\mathrm{org}}\right)\right)\right) \times 100 \\
\beta_{\mathrm{A} / \mathrm{B}}=\mathrm{D}_{\mathrm{A}} / \mathrm{D}_{\mathrm{B}} \\
\% \mathrm{~S}=\left([\mathrm{M}]_{\mathrm{aq}-\mathrm{s}} /[\mathrm{M}]_{\mathrm{org}}\right) \times 100
\end{gathered}
$$

where $[\mathrm{M}]_{0}$ and $[\mathrm{M}]_{\mathrm{aq}}$ represent the initial and metal concentration in the aqueous phase (raffinate), $\mathrm{V}_{\mathrm{aq}}$ and $\mathrm{V}_{\text {org }}$ represent the volumes of aqueous and organic phases, $\mathrm{A}$ and $\mathrm{B}$ represent different metals whose separation factor is the subject of determination, and $[\mathrm{M}]_{\mathrm{aq}-\mathrm{s}}$ and $[\mathrm{M}]_{\text {org }}$ are concentrations of metal ions in aqueous stripping solution and initial organic phase. All experimentally obtained data were processed as described.

Measured and calculated values are further used to construct McCabe-Thiele diagrams to determine the theoretical number of extraction/stripping stages.

In addition, the Sankey diagram was constructed to present the mass balance of the SX process under defined optimal conditions and to perceive the metal distribution.

\section{Results and Discussion}

\subsection{Feed Composition}

Casted anodes and electrolyte obtained by anodes electrorefining were chemically characterized in detail, and their composition is shown in Table 1. The chemical composition of minor components of smelting feed as well as of the process by-products are

\begin{tabular}{|c|c|c|c|c|c|}
\hline \multirow{2}{*}{ Element } & \multirow{2}{*}{$\begin{array}{c}\text { Metallic Granulate } \\
\%\end{array}$} & \multicolumn{2}{|c|}{ Anodes } & \multicolumn{2}{|c|}{ Electrolyte } \\
\hline & & $\%$ & ppm & $\mathrm{mg} / \mathrm{L}$ & $\mathrm{g} / \mathrm{L}$ \\
\hline $\mathrm{Cu}$ & 69.12 & 83.40 & - & - & 41.37 \\
\hline $\mathrm{Fe}$ & 5.90 & 3.90 & - & - & 20.67 \\
\hline $\mathrm{Zn}$ & 12.71 & 5.40 & - & - & 26.55 \\
\hline $\mathrm{Ni}$ & 1.68 & 2.32 & - & - & 9.89 \\
\hline Sn & 5.89 & 7.27 & - & 453.1 & - \\
\hline $\mathrm{Pb}$ & 3.30 & 3.52 & - & 3.1 & - \\
\hline $\mathrm{Bi}$ & n.a. & 0.04 & - & 112.9 & - \\
\hline $\mathrm{Ca}$ & n.a. & 0.10 & - & 346.3 & - \\
\hline $\mathrm{Co}$ & 0.01 & 0.05 & - & 163.4 & - \\
\hline $\mathrm{Cr}$ & 0.12 & 0.03 & - & 95.8 & - \\
\hline $\mathrm{Mg}$ & n.a. & 0.03 & - & 61.1 & - \\
\hline $\mathrm{Ag}$ & 0.64 & 0.64 & - & $<\mathrm{DL}$ & - \\
\hline $\mathrm{Au}$ & $30 \mathrm{ppm}$ & 0.11 & - & $<\mathrm{DL}$ & - \\
\hline $\mathrm{Al}$ & 0.12 & - & 63 & 19.3 & - \\
\hline $\mathrm{Cd}$ & 0.04 & - & 62 & 21.7 & - \\
\hline $\mathrm{Mn}$ & 0.10 & - & 84 & 29.7 & - \\
\hline B & n.a. & - & 32 & 8.7 & - \\
\hline $\mathrm{Na}$ & n.a. & - & 120 & 41.8 & - \\
\hline $\mathrm{Sb}$ & n.a. & - & 23 & 5.8 & - \\
\hline $\mathrm{Ga}$ & n.a. & - & 47 & 12.5 & - \\
\hline $\mathrm{Ge}$ & n.a. & - & 4 & 1.2 & - \\
\hline
\end{tabular}
not presented.

Table 1. Chemical composition of pyro-electro and solvent extraction feed (n.a., not analyzed; $<$ DL, below detection limit). 
As can be seen from Table 1, obtained products are characterized by extremely complex chemical composition, with a high concentration of $\mathrm{Cu}, \mathrm{Fe}, \mathrm{Zn}, \mathrm{Ni}$, and $\mathrm{Sn}$, and burdened with trace elements. This non-standard chemical composition and abundance of base and precious metals reflect the applied treatments' feed material composition and chemistry mechanisms. More specifically, during smelting, base $(\mathrm{Co}, \mathrm{Cu}, \mathrm{Ni}, \mathrm{Sn})$ and precious metals $(\mathrm{Au}$ and $\mathrm{Ag}$ ) are concentrated in blister copper. In addition, due to excluded step of oxidative anode refining prior to casting, impurities share in casted anodes is increased. Half of the $\mathrm{Zn}$ and a small share of Fe are lost by dissipation among smelting by-products (filter dust and slag). During electrorefining, metals from anodes are dissolved to the electrolyte, while most $\mathrm{Sn}, \mathrm{Pb}$, and precious metals are precipitated (as anode slime and suspended tin precipitate). The obtained values differ from the current electrolytes generated by traditional recycling by the dilution method of smelting feed. However, they are expected in the future if the smelting feed is predominantly or solely e-waste.

\subsection{Solvent Extraction (SX) Optimization}

\subsubsection{Effect of Extractant Concentrations and O/A Ratio}

A series of experiments were carried out to determine the effect of extractant concentration and $\mathrm{O} / \mathrm{A}$ ratio on the copper SX efficiency. The aqueous phase was raw electrolyte of $\mathrm{pH}$, and contact time was $10 \mathrm{~min}$ to ensure maximal mass transfer. The M5640 concentration vs. copper extraction efficiency plot was constructed (Figure 1). As can be seen, $\mathrm{Cu}$ extraction efficiency almost linearly increases with an increase of extractant concentration from $5 \%$ to $20 \%$, after which efficiency rises insignificantly. Moreover, it can be seen that, in the experiments with a phase ratio $\mathrm{O} / \mathrm{A}=1$ or less, $\mathrm{Cu}$ loading is below $14 \%$. It is presumed that, for $\mathrm{O} / \mathrm{A}$ below 1 , the predominance of raw electrolyte and its high acidity negatively affect extraction. Similar results are obtained for the co-extraction of the impurities (not shown).

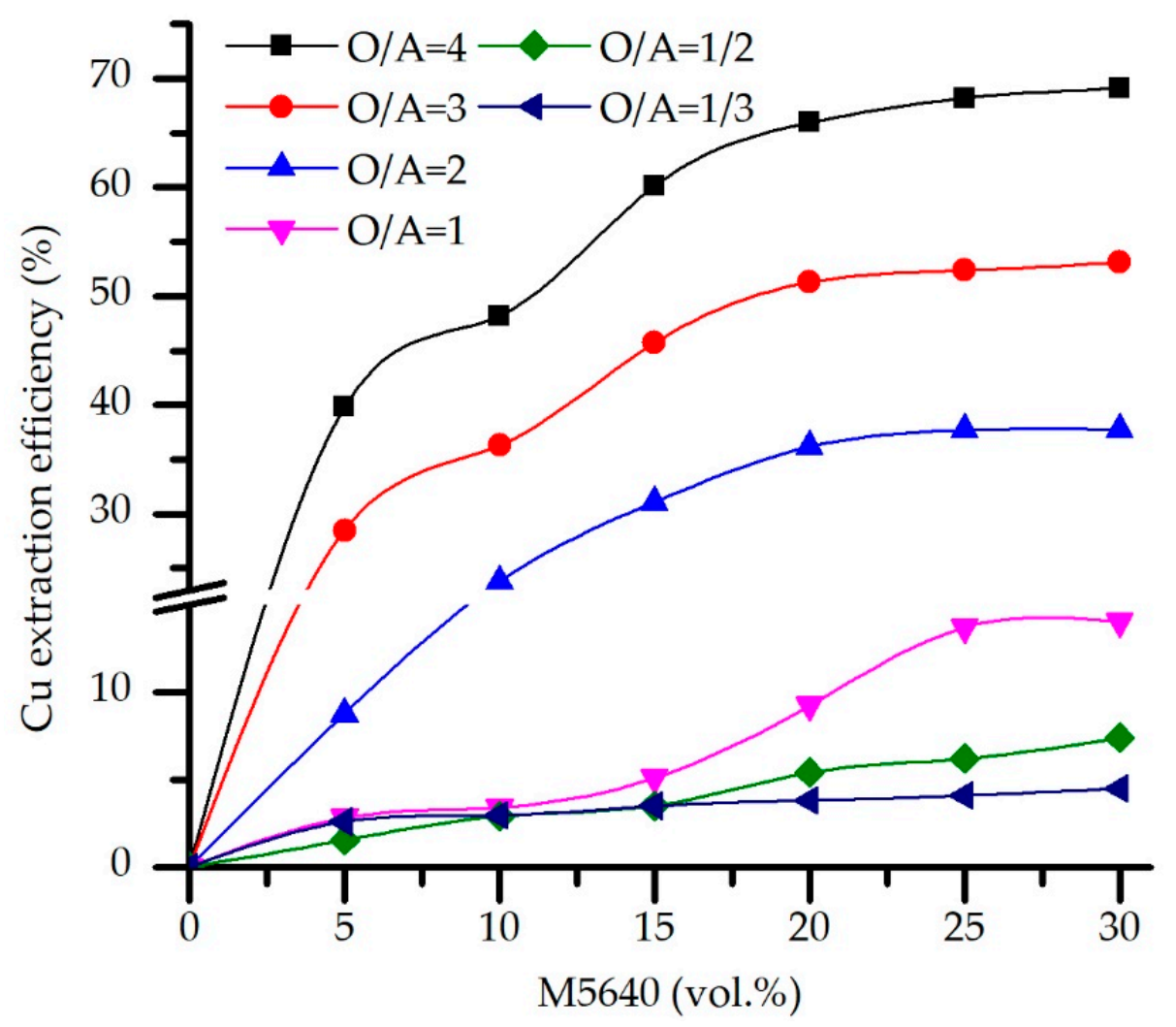

Figure 1. Copper extraction efficiency as a function of M5640 concentration and O/A phase ratio for the feed $\mathrm{pH}$, temperature $20^{\circ} \mathrm{C}$, and contact time $10 \mathrm{~min}$. 
According to what is stated above, a detailed analysis of extraction efficiencies and separation coefficients was performed only for $\mathrm{O} / \mathrm{A}$ ratios above 2 .

Figures 2 and 3 show the significant influence of extractant concentration and O/A ratio on extraction efficiency and $\mathrm{Cu}$ vs. impurities separation. Yet, the extraction of $\mathrm{B}$, $\mathrm{Ca}, \mathrm{Na}, \mathrm{Mg}, \mathrm{Pb}, \mathrm{Ga}$, and $\mathrm{Ge}$ do not occur at $\mathrm{O} / \mathrm{A}$ ratios above 2 in the whole extractant concentration range. Mentioned elements are co-extracted (below $3 \%$ ) only at $\mathrm{O} / \mathrm{A}=1 / 3$ when their feed input is the highest (not shown). As shown in Figures $2 a$ and $3 a$, at $\mathrm{O} / \mathrm{A}=2$, both extraction efficiency and separation coefficient are low so this phase ratio is excluded from subsequent optimization experiments. Further, at $\mathrm{O} / \mathrm{A}=3$ and 4 , extraction of the most abundant impurities slightly decreases with extractant concentration while $\mathrm{Cu}$ plateau is reached at M5640 20 vol.\%. Although at O/A = 4, Cu extraction efficiency is the highest, it is also the general co-extraction of accompanying metals, predominantly trace elements (Figure 2c). Therefore, Fe, Zn, Ni, and Sn loading, for M5640 20 vol.\%, is 6.9, 6.1, 4.1, and 7.4 at $\mathrm{O} / \mathrm{A}=3$ (Figure $2 \mathrm{~b}$ ), and significantly higher at $\mathrm{O} / \mathrm{A}=4$ : 14.4, 9.6, 10.05, and 19.80, respectively (Figure 2c).

The separation coefficient (Figure $3 b, c$ ) shows significant differences comparing $\mathrm{O} / \mathrm{A}=3$ and 4 ratios, but only at the upper M5640 concentration limit, which, as previously established, has not contributed to $\mathrm{Cu}$ extraction efficiency. For M5640 up to 20 vol. $\%$, better separation is achieved for $\mathrm{O} / \mathrm{A}=3$ ratio.

Extraction and selectivity results, as shown in Figures 2 and 3, respectively, could be explained by M5640 high affinity towards $\mathrm{Cu}$ versus other metals present in high concentrations, e.g., Ni, $\mathrm{Sn}, \mathrm{Fe}$, and $\mathrm{Zn}$. However, when copper extraction approaches saturation, due to the excess of the organic phase (at $\mathrm{O} / \mathrm{A}=4)$, the number of complexing centers available to extract accompanying (trace) metals increase, resulting in the coextraction of elevated impurities. Namely, according to Equation (1), the dimerization of extractant is necessary for $\mathrm{Cu}^{2+}$ extraction (Equation (6)):

$$
\mathrm{Cu}^{2+}+2 \mathrm{HA}=\mathrm{CuA}_{2}+2 \mathrm{H}^{+}
$$

This process is facilitated under high extractant concentration in the organic phase, which also allows the formation of the complexes with ions of higher valence than of $\mathrm{Cu}$ (i.e., $\mathrm{Bi}^{3+}, \mathrm{Sb}^{4+}$, and $\mathrm{Sn}^{4+}$ ). In addition, although a high co-extraction of $\mathrm{Fe}^{2+} /{ }^{3+}, \mathrm{Ni}^{2+}$, and $\mathrm{Zn}^{2+}$ could be expected based on their valence and extraction mechanism, this is not the case, probably due to their ionic radius and steric interference during di- and trimerization of the extractant. In the case of $\mathrm{Zn}^{2+}$, whose ionic radius is close to $\mathrm{Cu}^{2+}(74$ and $73 \mathrm{pm}$, respectively), the extraction of $\mathrm{Zn}$ is hindered, possibly due to the salting-out effect in a high sulfate concentration environment and the formation of $\mathrm{Zn}\left(\mathrm{SO}_{4}\right)_{2}{ }^{2-}$ instead of $\mathrm{Zn}^{2+}$. Considering that oximes do not extract anionic species at low $\mathrm{pH}, \mathrm{Zn}$ co-extraction is minimal. Thus, when the concentration of M5640 is $20 \mathrm{vol} \%$, and the O/A ratio is 3, the $\mathrm{Fe}, \mathrm{Zn}$, and $\mathrm{Ni}$ concentrations in the loaded organic phase were 1.4, 1.6, and $0.4 \mathrm{~g} / \mathrm{L}$. At the same time, Sn and Bi are measured in 34 and $41 \mathrm{ppm}$, respectively. The total concentration of trace metals was $25 \mathrm{ppm}$.

Comparing extraction efficiency and selectivity, considering impurities behavior, extractant (M5640) concentration of $20 \mathrm{vol} \%$, and O/A ratio of 3 was selected as optimal. In addition, the determined optimal concentration of M5640 in the organic phase is also beneficial considering that, for concentrations of M5640 higher than $25 \mathrm{vol} \%$, an increase in the viscosity of the organic phase was observed, leading to mixing difficulties and prolonged phase disengagement. 


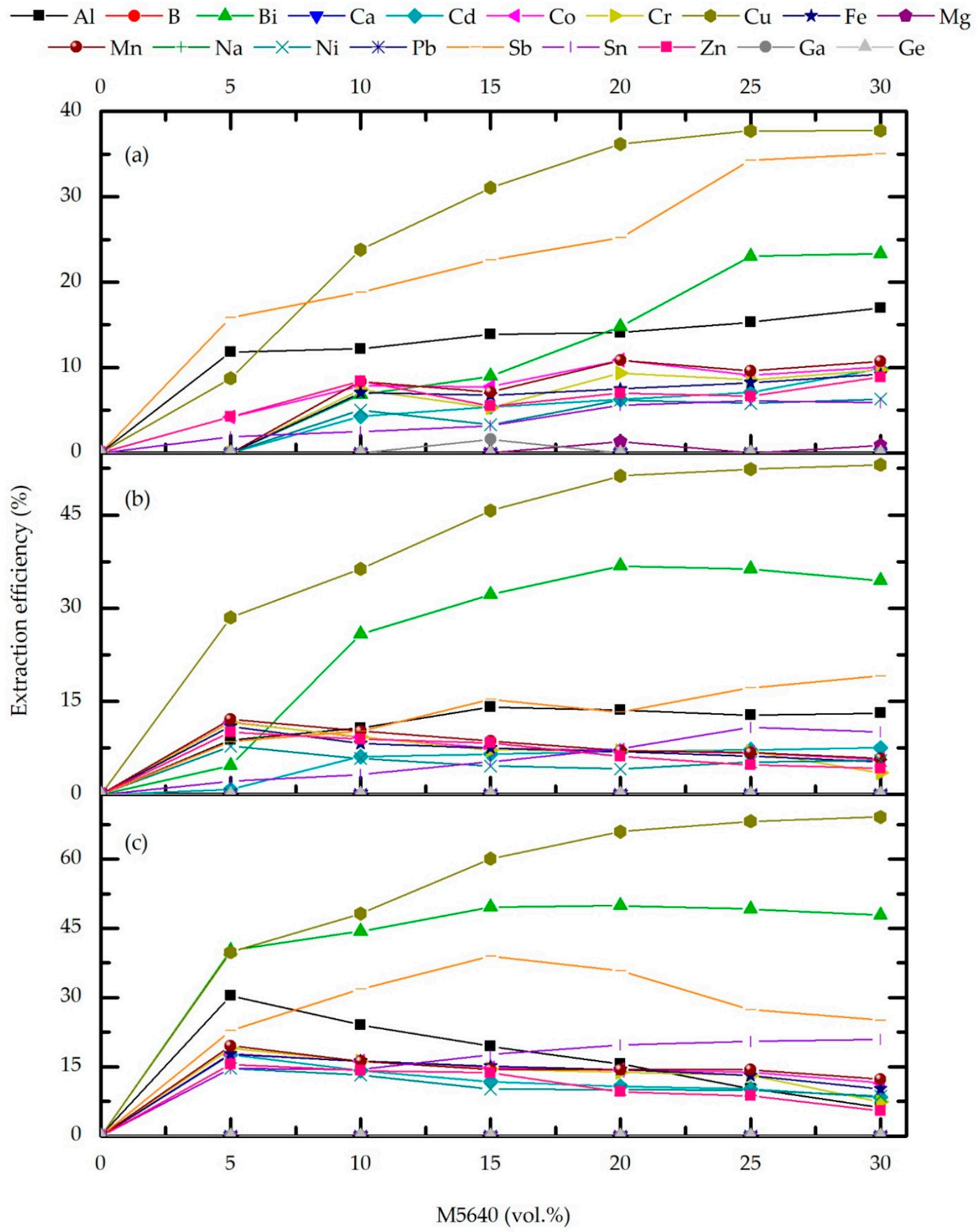

Figure 2. Effect of M5640 concentration and O/A phase ratio 4 (a), 3 (b), and 2 (c) on extraction efficiency for the feed pH 0 , temperature $20^{\circ} \mathrm{C}$, and contact time $10 \mathrm{~min}$. 


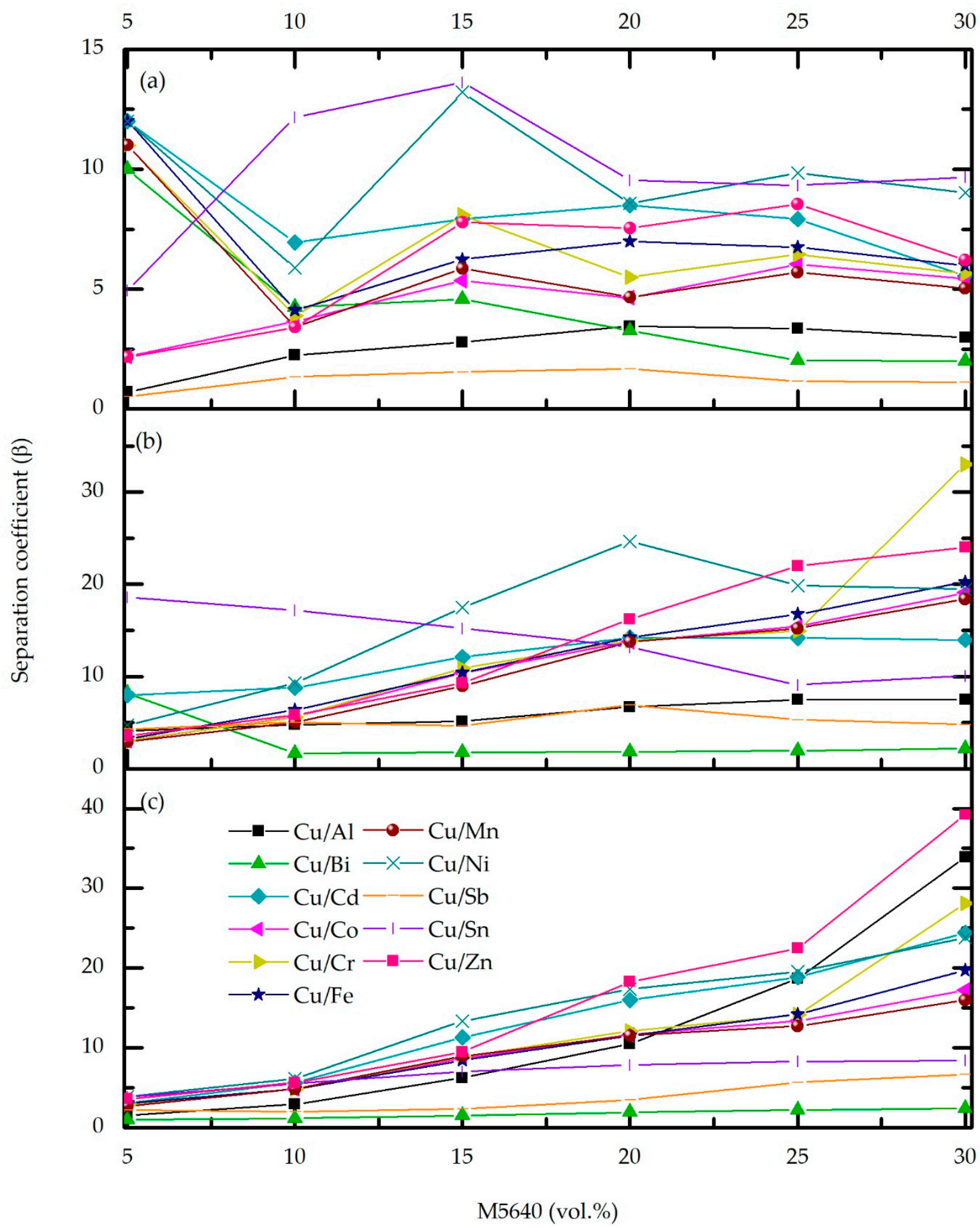

Figure 3. Effect of M5640 concentration and O/A phase ratio 4 (a), 3 (b), and 2 (c) on Cu-metal separation factor for the feed $\mathrm{pH}$, temperature $20^{\circ} \mathrm{C}$, and contact time $10 \mathrm{~min}$.

\subsubsection{Effect of Phase Contact Time}

In order to investigate the phase contact time effect (Figure 3), a set of experiments was conducted at previously optimized extractant concentration (20 vol. $\%$ ) and phase ratio $(\mathrm{O} / \mathrm{A}=3)$. As in previous experiments, the $\mathrm{pH}$ of the feed electrolyte was constant: 0 . The extraction efficiency of $\mathrm{Cu}$ and co-extraction of metal impurities were taken into account to determine the phase contact time parameter. 
As can be seen from Figure $4 a$, the extraction percentage generally rises with contact time. For the majority of trace metals, as well as for the most abundant impurities (Ni, $\mathrm{Sn}, \mathrm{Fe}$, and $\mathrm{Zn}$ ), the change in extraction efficiency is negligible. Moreover, prolonged contact time does not affect the extraction of $\mathrm{B}, \mathrm{Ca}, \mathrm{Na}, \mathrm{Mg}, \mathrm{Pb}, \mathrm{Ga}$, and $\mathrm{Ge}$, which remain in the raffinate. The extraction percentage of $\mathrm{Sb}$ sharply rises after $10 \mathrm{~min}$ of phase contact from $13.2 \%$ to $21.65 \%$, indicating slow extraction kinetics, while at this time point, $\mathrm{Cu}$ and Bi reach the plateau. These results can be explained by the strong binding capacity of $\mathrm{Cu}-\mathrm{M} 5640$ comparing to the other metals, leading to increased extraction until equilibrium is reached. After that point, the extraction of impurities rises. As shown in Figure 4b, the separation coefficient is influenced by phase contact time until the equilibrium of each metal is achieved, which for most of them is around $10 \mathrm{~min}$. Considering the contact time effect on the metal's behavior during extraction, the mentioned time point of 10 min makes a breaking point, and thus is it is chosen as the optimal one.

\subsubsection{Effect of Feed $\mathrm{pH}$}

In order to determine the influence of the acidity of the aqueous feed on the efficiency of $\mathrm{Cu}$ extraction, a series of experiments were conducted by varying the $\mathrm{pH}$ while the other process conditions were constant. According to Figure 5a, raising the feed $\mathrm{pH}$ from 0 to 2, the effect on the co-extraction of the $\mathrm{Fe}, \mathrm{Zn}, \mathrm{Ni}$, and $\mathrm{Sn}$ was negligible, and overall extraction was below $8 \%$. Moreover, trace elements loading is slightly affected by feed $\mathrm{pH}$. The most drastic change in the extraction, affected by feed acidity, was observed for Cu loading, which increased from $51.30 \%$ to $98.87 \%$ in the experimental $\mathrm{pH}$ range. High Cu extraction efficiency at elevated feed $\mathrm{pH}$ can be expected, having in the mind extraction mechanism and $\mathrm{H}^{+}$influence on the reaction equilibrium (Equation (6)). Thus, in the extremely high acidity conditions, during the extraction step, simultaneous re-extraction occurs, leading to stripping of $\mathrm{Cu}$ from the organic phase. This effect is absent at elevated $\mathrm{pH}$ values. In addition, high $\mathrm{pH}$ favors the ionization of the extractant, facilitating metal extraction. The latter statement contradicts the results obtained for the extraction of impurities which would be expected to also increase with increasing $\mathrm{pH}$ which is obviously not the case. The explanation lies in $\mathrm{Cu}$ loading, as with increasing copper complexation, the competitive reactions of metal impurities do not come to the fore and their loading remains low. This best reflects the separation factor (Figure 5b) which apparently increases after $\mathrm{pH} 1.5$ when the $\mathrm{Cu}$ loading reaches about $90 \%$.

According to the experimental results, an increasing trend of $\mathrm{Cu}$ extraction is evident, yet at the mentioned upper $\mathrm{pH}$ limit the plateau was not achieved. However, additional experiments with an extended $\mathrm{pH}$ range were not feasible due to the precipitation of mostly $\mathrm{Fe}^{3+}$ hydroxide and co-precipitation of $\mathrm{Cu}$, which led to its loss. Moreover, at $\mathrm{pH} 2$, slight turbidity of aqueous feed occurs, presumably due to iron hydroxide formation, and experiments showed extended phase separation time. Considering the obtained results, $\mathrm{pH} 1.5$ was the optimal choice.

\subsubsection{McCabe-Thiele Extraction Diagram}

In order to determine the number of the extraction stages, a correlation diagram between metal content in the organic vs. aqueous phase was plotted. The $\mathrm{Cu}$ extraction isotherm was constructed according to the experimental results obtained by various $\mathrm{O} / \mathrm{A}$ ratios maintaining extractant concentration, phase contact time, feed $\mathrm{pH}$, and temperature constant. A McCabe-Thiele diagram (Figure 6) was constructed assuming that the concentration of the $\mathrm{Cu}$ in the organic phase was $0 \mathrm{~g} / \mathrm{L}$. Results show three theoretical stages needed to achieve quantitative copper extraction. 


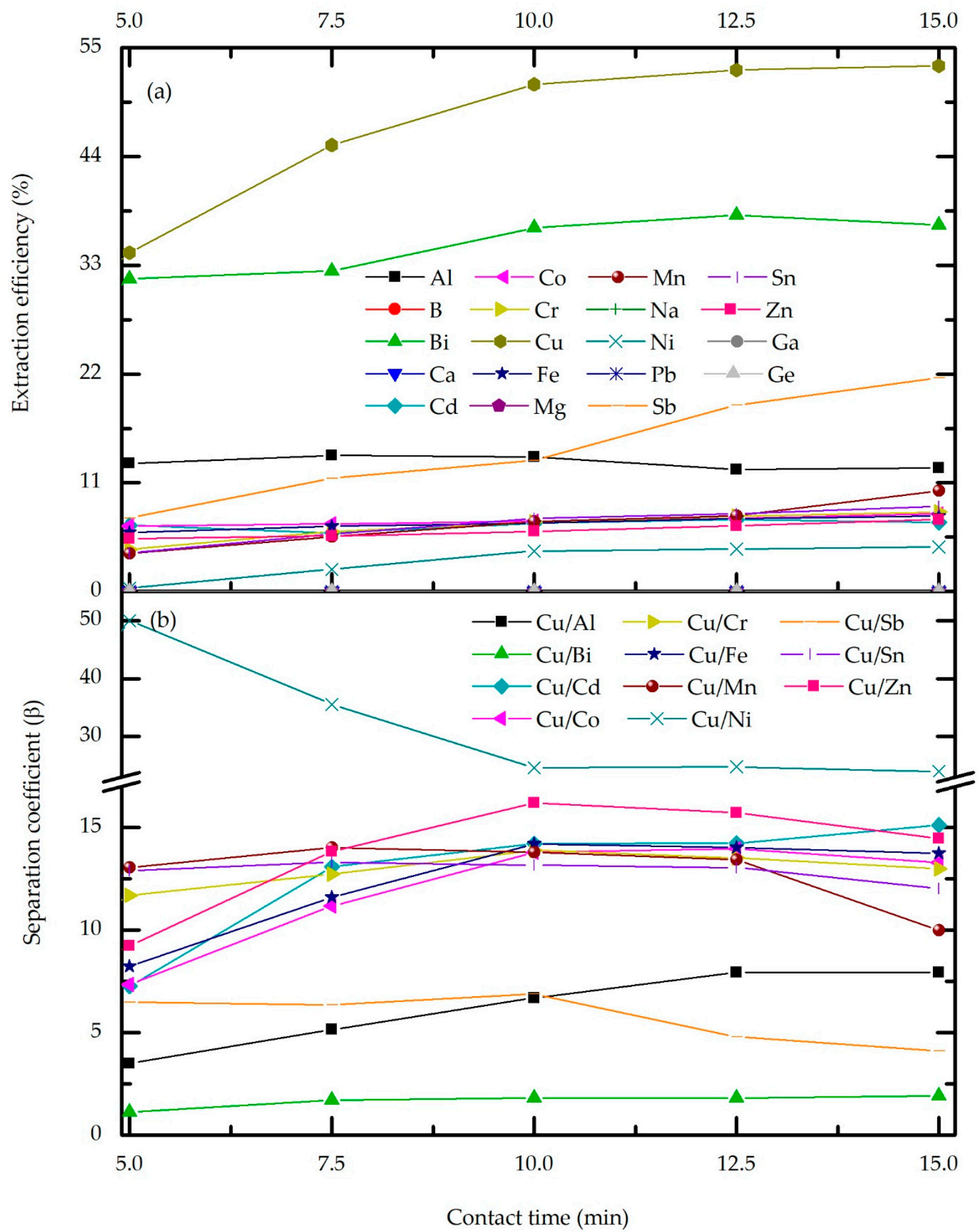

Figure 4. Effect of phase contact time: extraction efficiency (a), and separation coefficient (b) for the feed $\mathrm{pH} 0, \mathrm{M} 5640$ 20 vol. $\%, \mathrm{O} / \mathrm{A}=3$ and temperature $20^{\circ} \mathrm{C}$. 


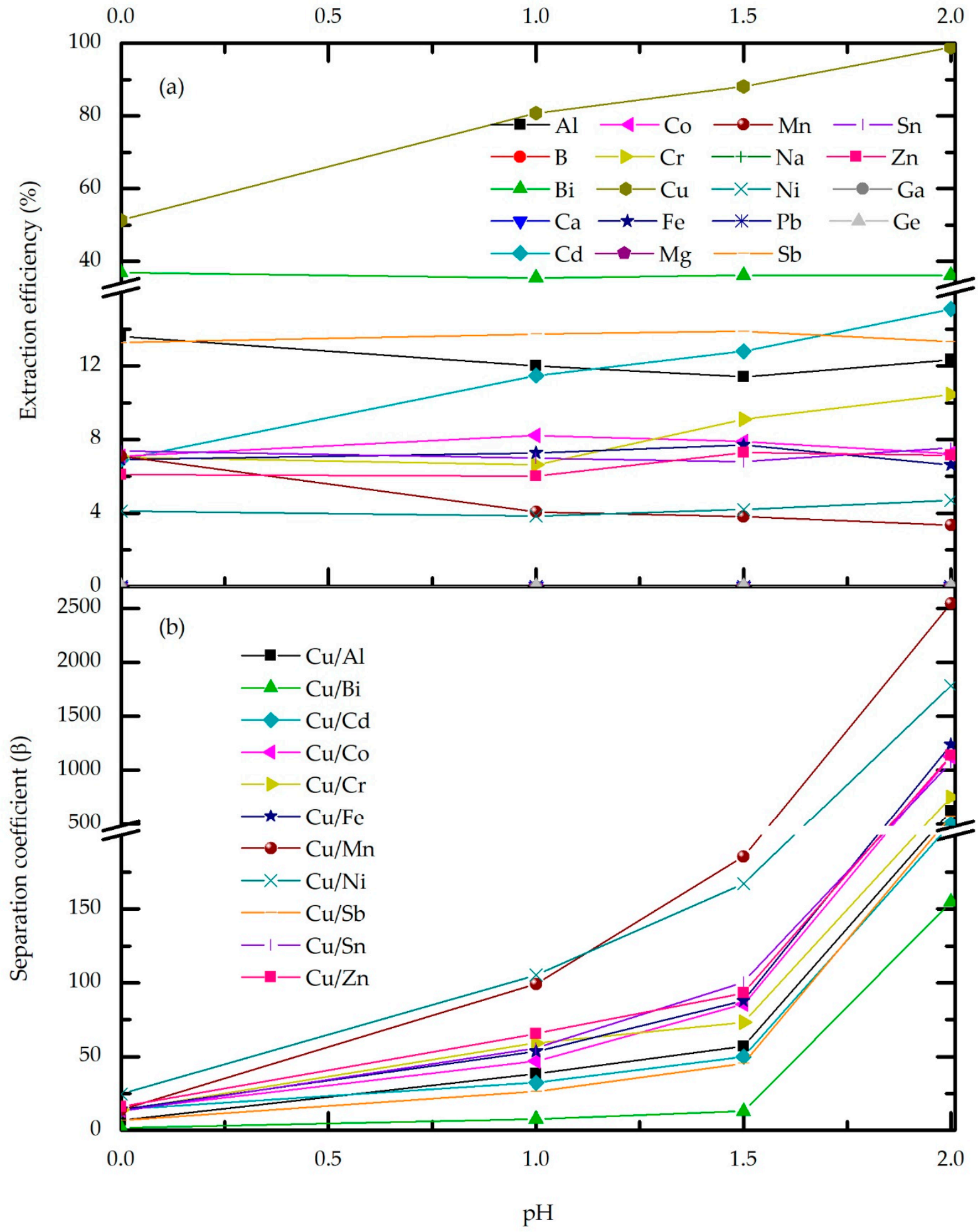

Figure 5. Effect of feed $\mathrm{pH}$ on the extraction efficiency (a) and Cu-metal separation factor (b) for M5640 20 vol.\%, O/A = 3, temperature $20^{\circ} \mathrm{C}$ and contact time $10 \mathrm{~min}$. 


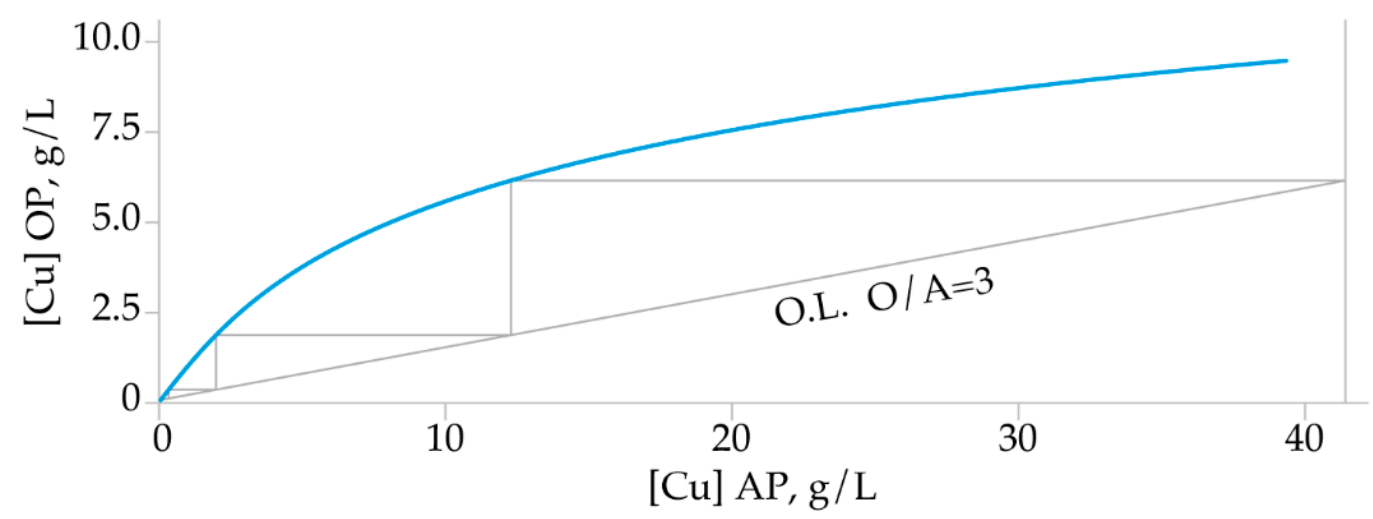

Figure 6. McCabe-Thiele extraction diagram.

\subsection{Stripping Optimization}

\subsubsection{Effect of the Acid Concentration}

In order to strip copper from the loaded organic phase, sulfuric acid, as suitable for downstream $\mathrm{Cu}$ recycling, i.e., electrowinning, was chosen as a stripping agent. A series of stripping experiments were conducted to determine the effect of the acid concentration on the stripping efficiency and to choose the optimal one. Parameters, such as loaded organic phase extractant concentration (M5649 20 vol.\%), temperature $20{ }^{\circ} \mathrm{C}, \mathrm{O} / \mathrm{A}$ ratio 2, and contact time $5 \mathrm{~min}$, were kept constant.

As shown in Figure 7, high efficiency of $\mathrm{Cu}$ stripping was achieved in the investigated acid concentration range. By increasing concentration from 100 to $180 \mathrm{~g} / \mathrm{L} \mathrm{H}_{2} \mathrm{SO}_{4}$, the stripping efficiency of $\mathrm{Cu}$ is increased from 65.2 to $95.3 \%$. A further increase, to $200 \mathrm{~g} / \mathrm{L}$ $\mathrm{H}_{2} \mathrm{SO}_{4}$, only slightly increases efficiency, to $96.2 \%$. Higher concentrations of stripping agent were not considered due to the slight effect on $\mathrm{Cu}$ stripping and the possible negative effect on the extract, i.e., hydrolytic degradation.

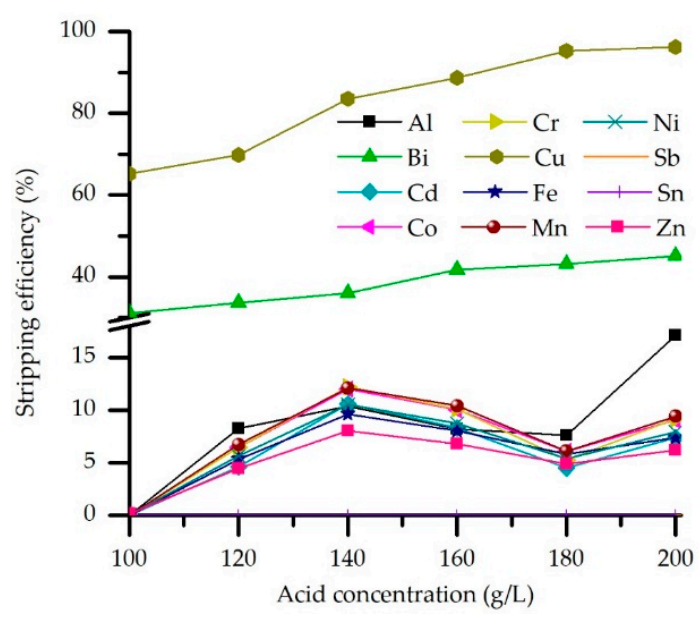

Figure 7. Effect of the $\mathrm{H}_{2} \mathrm{SO}_{4}$ concentration on the stripping efficiency (M5640 20 vol.\% in loaded OP, $\mathrm{O} / \mathrm{A}=2$, temperature $20^{\circ} \mathrm{C}$, and contact time $5 \mathrm{~min}$ ).

These results are following the extraction mechanism and the influence of $\mathrm{H}^{+}$ions on the reaction equilibrium (Equation (6)). Increased concentration of the $\mathrm{H}^{+}$ions provides near quantitative metal replacement from its organic complex. Two protons are needed for every $\mathrm{CuA}_{2}$ complex, while for metals of higher valence, replacement demands more protons (Equations (7) and (8)).

$$
\mathrm{CuA}_{2}+2 \mathrm{H}^{+}=2 \mathrm{AH}+\mathrm{Cu}^{2+},
$$




$$
\mathrm{BiA}_{3}+3 \mathrm{H}^{+}=3 \mathrm{AH}+\mathrm{Bi}^{3+} .
$$

However, the selectivity of $\mathrm{Cu}$ stripping is hindered by $\mathrm{Bi}$, which is co-stripped up to $45 \%$. On the other hand, $\mathrm{Sb}$ and $\mathrm{Sn}$ cannot be stripped under described experimental conditions and remain in the organic phase. Stripping efficiency of other trace metals and $\mathrm{Fe}, \mathrm{Zn}$, and $\mathrm{Ni}$, was under $15 \%$. The predominance of the $\mathrm{Cu}$ in the organic phase and affinity in the metal- $\mathrm{A}_{\mathrm{n}}-\mathrm{H}^{+}$system could explain obtained results. Namely, under optimal extraction conditions, the loaded organic phase contains $36.5 \mathrm{~g} / \mathrm{L} \mathrm{Cu}$ and significantly less metal impurities: $1.6 \mathrm{~g} / \mathrm{L} \mathrm{Zn,} 1.9 \mathrm{~g} / 1 \mathrm{Fe}$, while Ni, Sn, and Bi are measured in ppm 415,31 , and 41, respectively. The concentration of other metal impurities is under $30 \mathrm{ppm}$. According to the results, $180 \mathrm{~g} / \mathrm{L} \mathrm{H}_{2} \mathrm{SO}_{4}$ is chosen as the optimal concentration of the stripping agent and thus applied in the subsequent experiments.

\subsubsection{Effect of $\mathrm{O} / \mathrm{A}$ Stripping Ratio}

Another set of experiments were conducted to determine the $\mathrm{O} / \mathrm{A}$ ratio effect on the stripping efficiency. As before, all other process parameters were kept constant. Results are shown in Figure 8. Accordingly, the $\mathrm{O} / \mathrm{A}$ ratio effect on $\mathrm{Cu}$ and Bi stripping efficiency has a negligible effect on trace elements and $\mathrm{Fe}, \mathrm{Zn}$, and $\mathrm{Ni}$. Copper stripping efficiency sharply rises to $\mathrm{O} / \mathrm{A}=2$, after which only a slight increase is observed, from 95.3 to $97.2 \% \mathrm{~S}$, while $\mathrm{Bi}$ co-stripping almost linearly increases in the whole experimental O/A range. Meanwhile, other impurities are stripped up to $8 \%$ by the upper $\mathrm{O} / \mathrm{A}$ range limit.

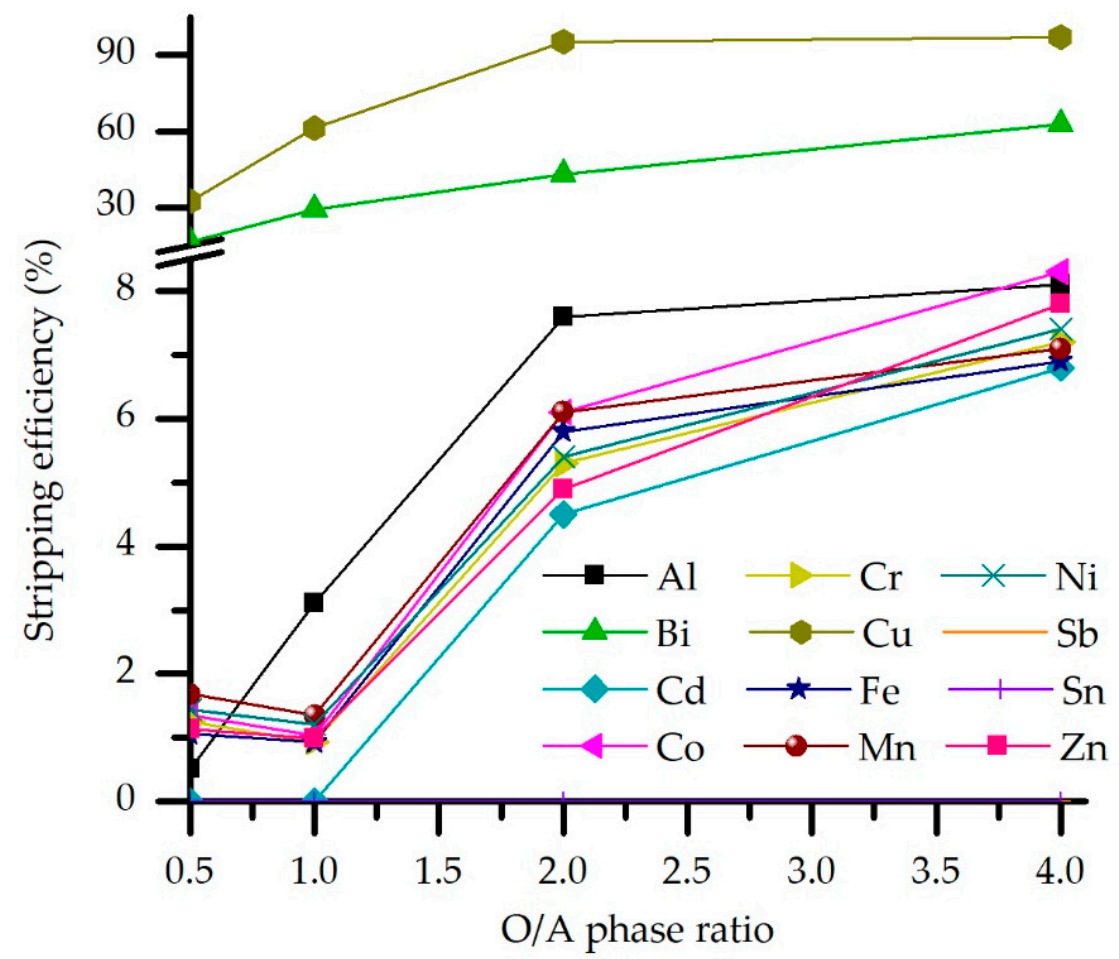

Figure 8. Effect of the phase ratio on the stripping efficiency (M5640 20 vol. \% in loaded $\mathrm{OP}, \mathrm{H}_{2} \mathrm{SO}_{4}$ concentration $180 \mathrm{~g} / \mathrm{L}$, temperature $20^{\circ} \mathrm{C}$, and contact time $5 \mathrm{~min}$ ).

The O/A effect can be explained by the amount of metals input in the system through the loaded organic phase. As the amount of metal available for striping increases, so does stripping. However, $\mathrm{Cu}$ predominance in the loaded organic phase results in its near quantitative stripping due to the crowding effect of copper on the extraction of metal impurities.

Keeping in mind the optimal extraction ratio $(\mathrm{O} / \mathrm{A}=3)$, it would be preferable for the stripping ratio to be greater than 3 to avoid general dilution of the $\mathrm{Cu}$ solution. Yet, 
experimental results showed low selectivity for $\mathrm{O} / \mathrm{A}$ stripping ratio even above 2 , so according to this, $\mathrm{O} / \mathrm{A}=2$ was chosen as the optimal ratio for the $\mathrm{Cu}$ stripping from the loaded organic phase.

\subsubsection{Effect of Stripping Contact Time}

In order to determine the effect of contact time on the stripping efficiency and selectivity, this parameter is varied in the 2.5 to $15 \mathrm{~min}$ range. In contrast, other parameters were constant, following previously determined optimal values. Results (Figure 9) indicate that prolonged contact time leads to an increase in the percentage of impurities stripped from the loaded organic phase, especially in the case of $\mathrm{Bi}$, whose stripping efficiency generally rises from $44 \%$ to $67 \%$ within the studied time range.

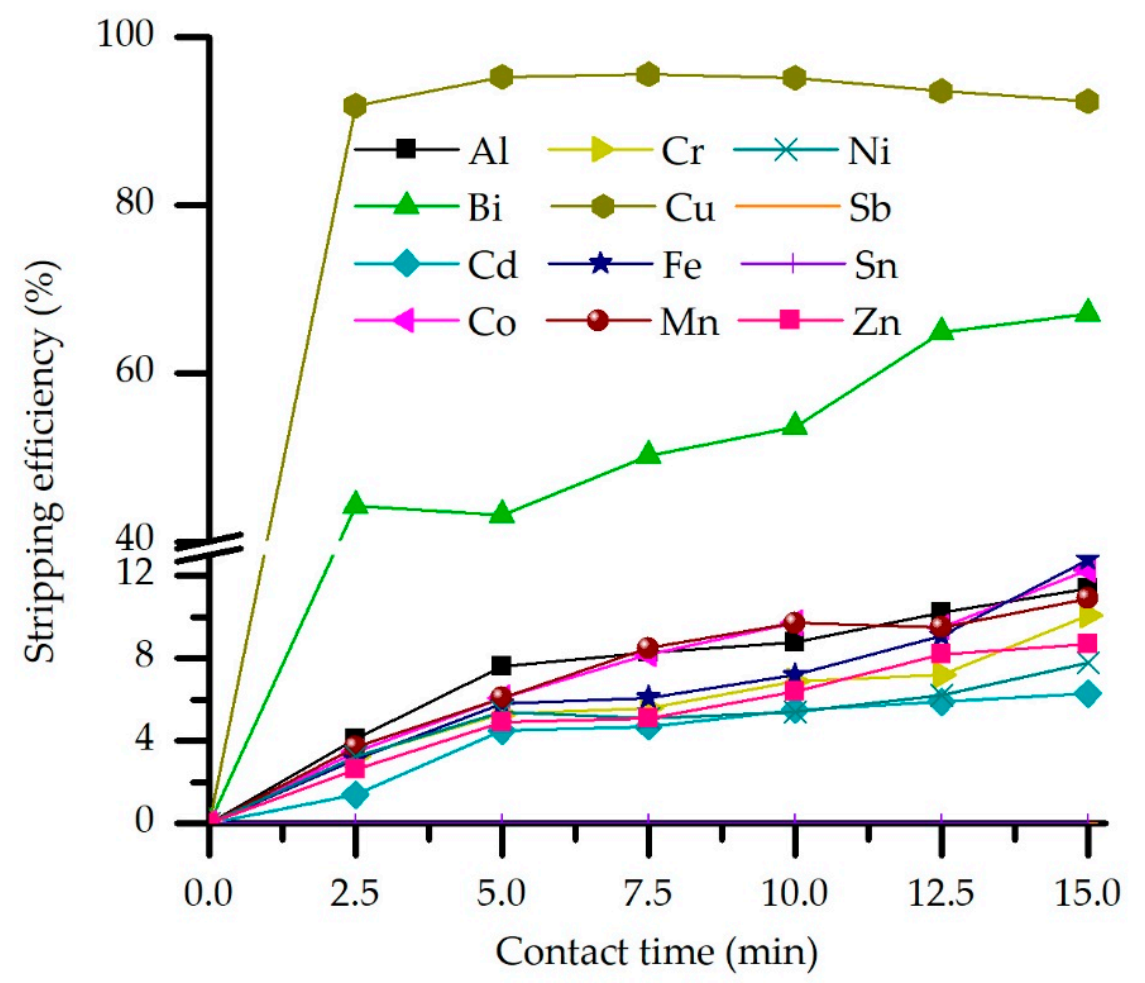

Figure 9. Effect of the phase contact time on the stripping efficiency (M5640 20 vol.\% in loaded OP, $\mathrm{H}_{2} \mathrm{SO}_{4}$ concentration $180 \mathrm{~g} / \mathrm{L}, \mathrm{O} / \mathrm{A}=2$, and temperature $20^{\circ} \mathrm{C}$ ).

Accordingly, impurities seem to have slower stripping kinetics than copper, the stripping of which shows a slight decrease after $5 \mathrm{~min}$ of phase contacting, achieving the equilibrium at this time point. In addition, almost $92 \%$ of $\mathrm{Cu}$ is stripped at the lower time range border, indicating fast stripping kinetic under studied process conditions. According to the obtained experimental results, a short contact time would be preferred to achieve high $\mathrm{Cu}$ loading while leaving the impurities in the organic phase. Thus, $5 \mathrm{~min}$ was chosen as the optimal stripping contact time.

\subsubsection{Effect of Extractant Concentration in the Loaded Organic Phase}

The loaded organic phase of different extractant concentrations was used as metal feed, and $\mathrm{Cu}$ stripping experiments were conducted under previously defined optimal conditions $\left(\mathrm{O} / \mathrm{A}=2,180 \mathrm{~g} / \mathrm{L} \mathrm{H}_{2} \mathrm{SO}_{4}\right.$, contact time $5 \mathrm{~min}$, and temperature $\left.20^{\circ} \mathrm{C}\right)$. Results shown in Figure 10 indicate hindered stripping, as reflected in the decrease of stripping efficiency (from 95.3 to $72.6 \%$ ) for experiments of extractant concentration (M5640) above 20 vol.\%. This can be explained by elevated extraction efficiency when the extractant concentration is above the mentioned value due to pronounced Cu-M5640 binding affinity 
and increased $\mathrm{Cu}$ abundance in the organic phase. Such stripping results favor the previous experimentally defined optimal extractant concentration.

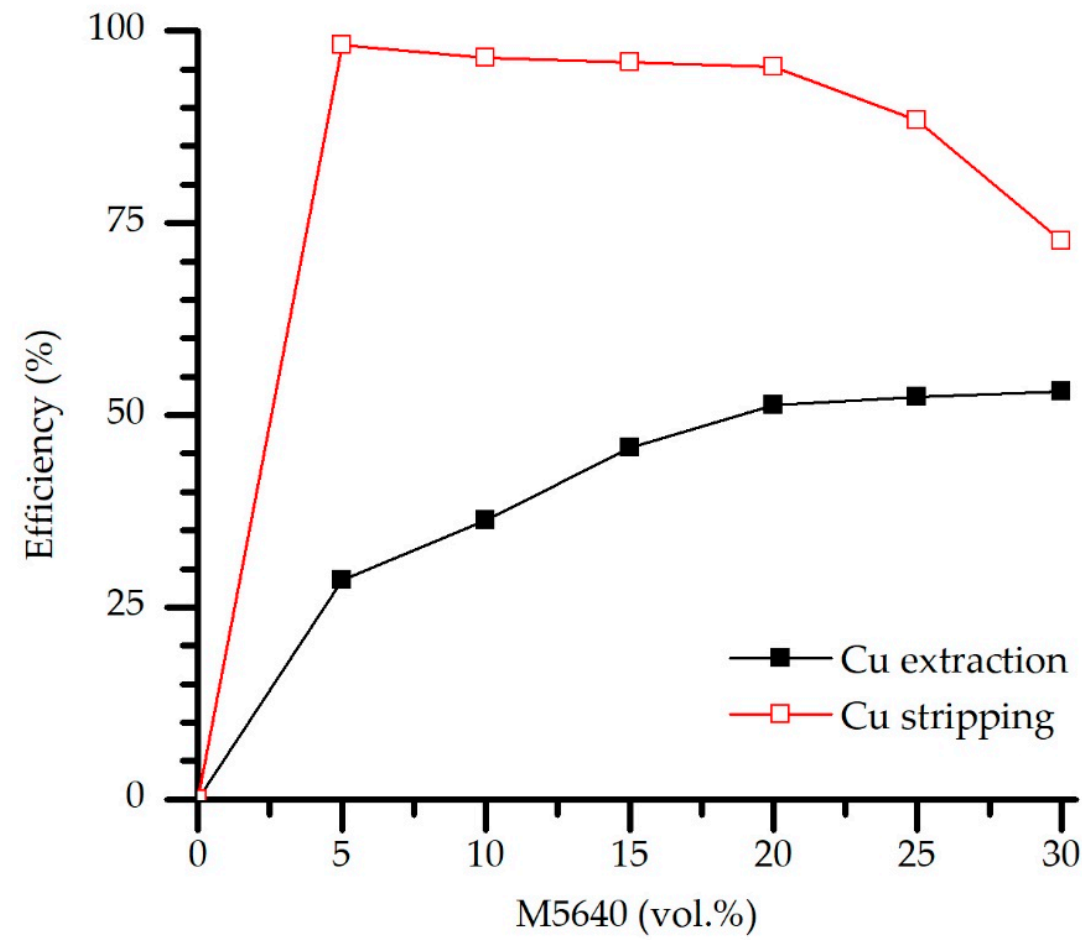

Figure 10. Extraction-stripping efficiency correlation-effect of the extractant concentration in the loaded OP on the stripping efficiency $\left(\mathrm{H}_{2} \mathrm{SO}_{4} 180 \mathrm{~g} / \mathrm{L}, \mathrm{O} / \mathrm{A}=2\right.$, contact time $\left.5 \mathrm{~min}\right)$.

\subsubsection{McCabe-Thiele Stripping Diagram}

The distribution isotherm of $\mathrm{Cu}$ stripping from the loaded organic phase was plotted according to the results obtained under previously defined optimal experimental conditions: $20 \mathrm{vol} . \%$ of extractant concentration in the loaded organic phase, $180 \mathrm{~g} / \mathrm{L} \mathrm{H}_{2} \mathrm{SO}_{4}$ as stripping agent, and phase contact time $5 \mathrm{~min}$ at $20^{\circ} \mathrm{C}$. Phase ratios were varied from 0.5 to 4. According to the constructed McCabe-Thiele diagram (Figure 11), two theoretical stages are needed to strip $\mathrm{Cu}$ from the loaded organic phase quantitatively.

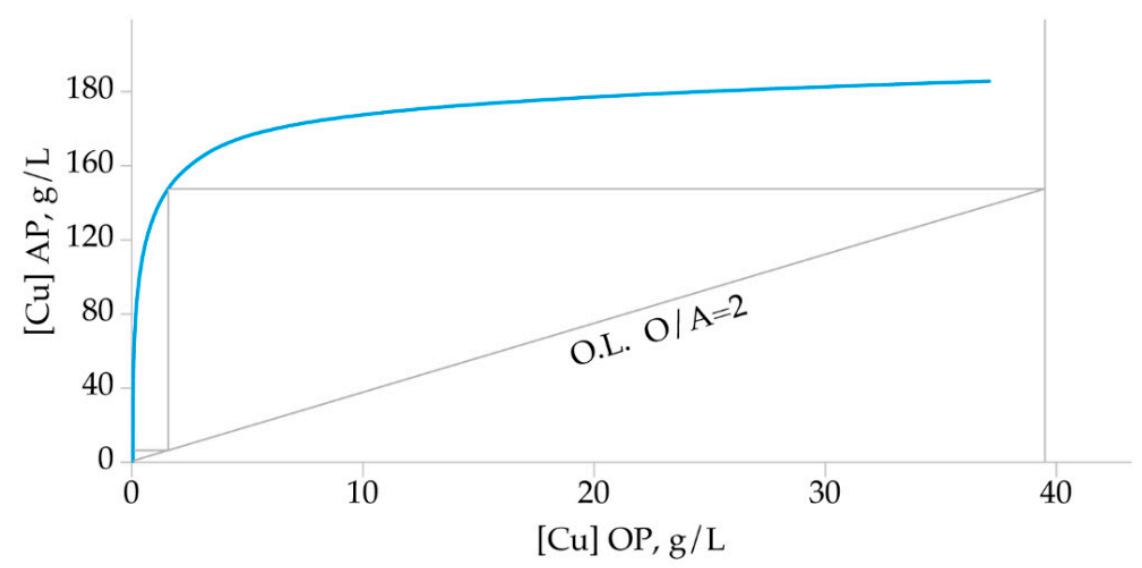

Figure 11. McCabe-Thiele stripping diagram.

\subsection{Solvent Extraction with LIX ${ }^{\circledR} 984 \mathrm{~N}$ and OPT 5510}

In order to select the most efficient extractant for copper extraction from a complex system, a series of experiments were conducted using, in addition to M5640, two other 
commercial extractants: LIX ${ }^{\circledR}$ 984N (often used for Cu extraction from sulfate solutions) and OPT 5510 (an extractant modified to facilitate $\mathrm{Cu}$ extraction and stripping). According to the obtained results, all three studied reagents show high $\mathrm{Cu}$ extraction efficiency (Figure 12). However, although the highest $\mathrm{Cu}$ loading was achieved with LIX ${ }^{\circledR} 984 \mathrm{~N}$, so was impurity co-extraction, especially with $\mathrm{Fe}$, which reaches almost $50 \%$. Co-extraction of $\mathrm{Zn}, \mathrm{Ni}, \mathrm{Bi}$, and $\mathrm{Sn}$ is significant, both with $\mathrm{LIX}^{\circledR}$ and OPT. Moreover, selectivity is achieved only by M5640. As for the extraction, the subsequent stripping step also shows favorable $\mathrm{Cu}$ results for all three studied reagents, with slightly promoted stripping from loaded M5640. However, the co-stripping of impurities from loaded LIX ${ }^{\circledR} 984 \mathrm{~N}$ and OPT 5510 is elevated, showing poor selectivity towards $\mathrm{Cu}$. In addition, under applied experimental conditions, Sn cannot be stripped from the loaded M5640, yet for the other two extractants it is up to $5 \%$. The trace metals impurities follow a similar trend of increased extraction with LIX ${ }^{\circledR} 984 \mathrm{~N}$ and OPT 5510 for both SX process steps (not shown).

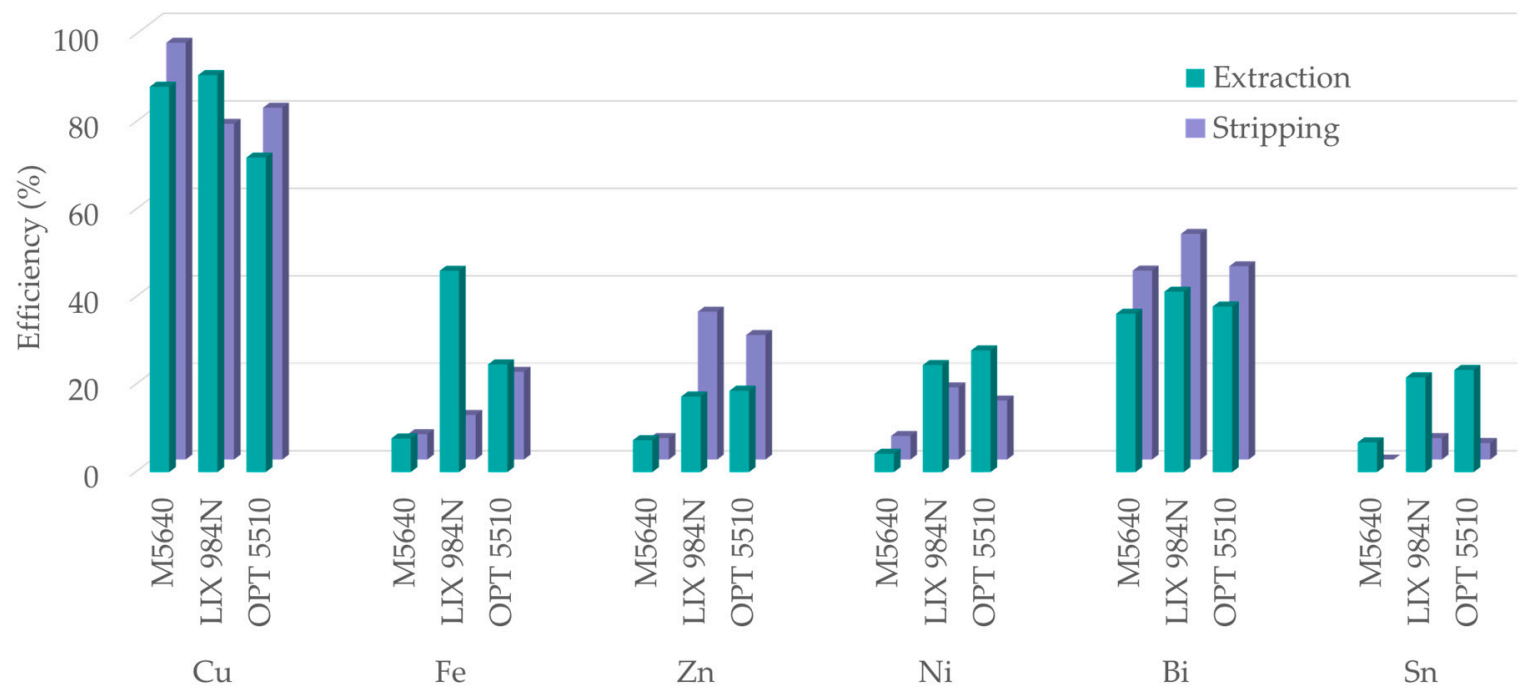

Figure 12. Comparison of extraction (for extractant concentration $20 \mathrm{vol} \%$, feed $\mathrm{pH} 1.5, \mathrm{O} / \mathrm{A}=3$, contact time $10 \mathrm{~min}$ ) and stripping $\left(\mathrm{H}_{2} \mathrm{SO}_{4} 180 \mathrm{~g} / \mathrm{L}, \mathrm{O} / \mathrm{A}=2\right.$, contact time $5 \mathrm{~min}$ ) efficiency of the three studied extractants (one stage SX conducted at $\left.20^{\circ} \mathrm{C}\right)$.

The active species of the extractants could explain the obtained results. Specifically, dissolved $\mathrm{Cu}$ cations in sulfuric acid are solvated, $\left(\mathrm{Cu}\left(\mathrm{H}_{2} \mathrm{O}\right)_{m}\right)^{\mathrm{n}+}$ and the coordination of these complexes affects $\mathrm{CuA}_{2}$ stability through the intermediate formation. This depends on the acidity of the extractant active group: the extractants with stronger acidic groups, i.e., aldoxime, facilitate $\mathrm{Cu}$ transfer compared with the less acidic active group, i.e., ketoxime one [37]. On the other hand, considering the chemical composition of the studied extractants, due to the weaker MAn bond in ketoxime complexes, stripping is facilitated. In complex solutions, such as the one studied in this paper, aldoxime-ketoxime extractants LIX ${ }^{\circledR} 984 \mathrm{~N}$ and OPT 5510 allow high metal transfer to the organic phase and facilitate stripping, leading to decreased selectivity, both for extraction and stripping steps. In addition, the ketoxime active group, OPT, contains an ester modifier that facilitates $\mathrm{Cu}$ extraction and stripping. This OPT feature seems to favor clean systems unburdened by impurities, yet for complex systems, as in this study, it is undesirable, causing low selectivity with high co-extraction percent.

Comparing the obtained experimental results, it is clear that M5640 is the optimal choice for the extractant. The general results for metals behavior using LIX ${ }^{\circledR} 984 \mathrm{~N}$ and OPT 5510 as extractants perhaps could be more efficient under different SX conditions. This remains for further investigation. 


\subsection{Copper and Metal Impurities Distribution}

Based on the experimentally obtained results and calculated values of extraction and stripping efficiencies obtained under optimal process conditions, a diagram of the distribution of the elements through the one-stage SX process (Sankey diagram) is constructed (Figure 13). It should be noted that the width of the lines is proportional to the mass transfer through phases, except for the most trace elements, for which the width of the lines is slightly increased for visualization purposes.

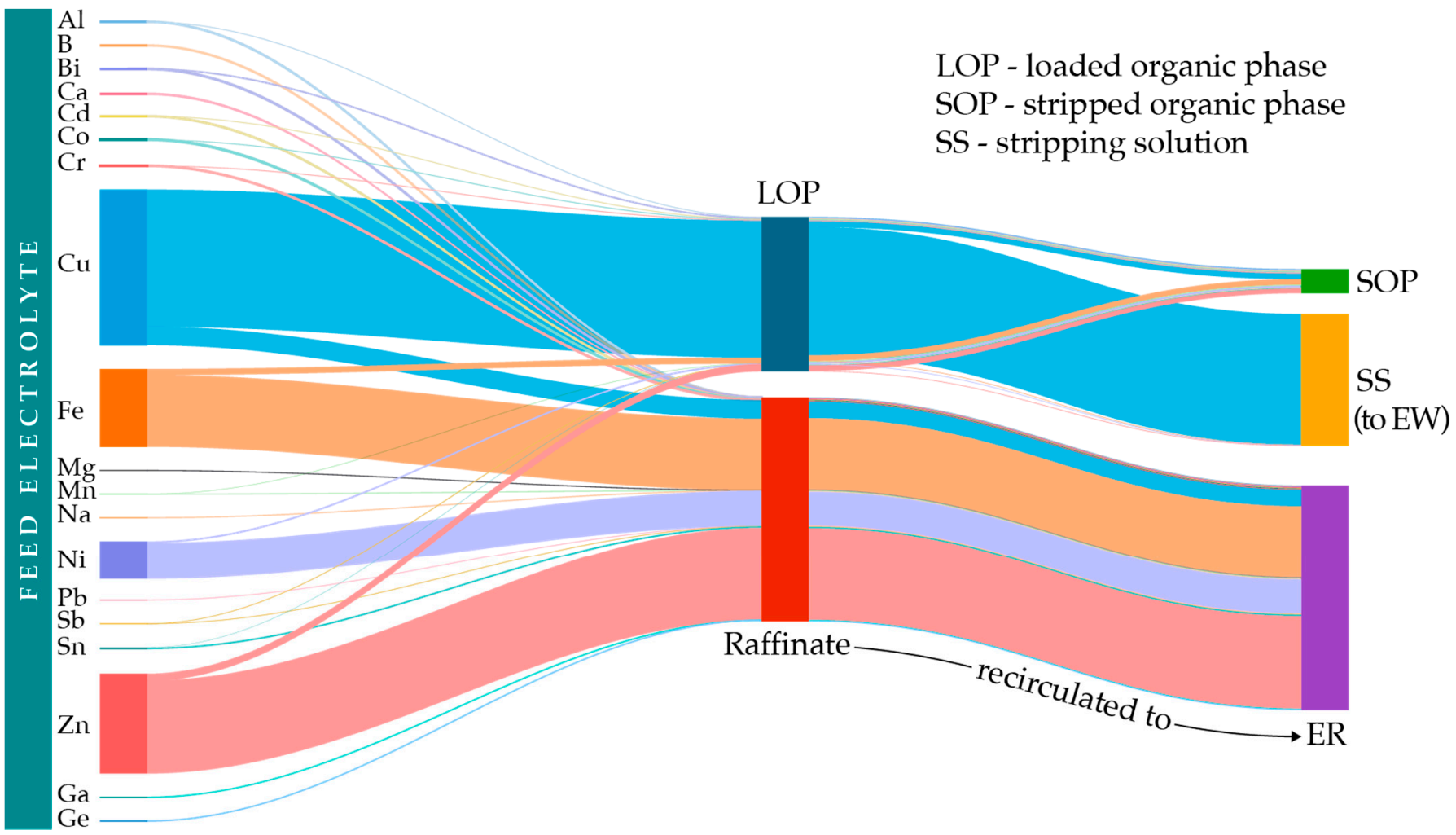

Figure 13. Metal distribution and mass balance of SX process.

By monitoring the impurities transfer through phases, the determined distribution showed that, under the applied conditions, $\mathrm{B}, \mathrm{Ca}, \mathrm{Mg}, \mathrm{Na}, \mathrm{Pb}, \mathrm{Ga}$, and $\mathrm{Ge}$ are not extracted but remain entirely in the raffinate. Moreover, over $90 \%$ of each trace element remained in the raffinate, as did the most abundant impurities $\mathrm{Fe}, \mathrm{Zn}, \mathrm{Ni}$, and $\mathrm{Sn}$. The raffinate is not discarded but returned in the upstream process of ER. Furthermore, after selective stripping of the $\mathrm{Cu}$, most of the previously extracted quantities of the trace elements were retained in the loaded organic phase. Considering their concentration under $30 \mathrm{ppm}$, a significant effect of the extractant performance is not expected in a repeated process. In addition, reuse of the OP leads to the accumulation of trace metals, allowing their valorization in additional steps, including traditional methods of stripping with a suitable agent. Additionally, implementation of the water wash (scrubbing stage at low acidities) could be an option to remove Fe and other contaminants acting as poison to the organic phase.

Further, the stripping solution obtained under defined process conditions is relieved of impurities, especially Fe: from $20.67 \mathrm{~g} / \mathrm{L}$ in feed, Fe concentration decreased to $92 \mathrm{ppm}$ in stripping solution, which is 10 times less than the maximal recommended concentration in solution for the downstream $\mathrm{Cu}$ EW process, as stated in Section 1.

Having in mind the recirculation of the process solutions, accumulation of the retained elements is inevitable. However, this fact enables effective the extraction of metal values through additional stages. The buildup effect increases the concentration of valuable elements, i.e., $\mathrm{Ga}$ and $\mathrm{Ge}$ belong to critical technological metals whose extraction is cost- 
effective and feasible from concentrated solutions [38]. Moreover, increased Sn, Ni, Fe, and $\mathrm{Zn}$ concentrations in the $\mathrm{Cu}$ unladen raffinate facilitates the separation and valorization of these metals. Fe can be extracted from sulfuric solution by P507 [39] or MOC 55 [40]. Further, Ni and Zn could be separated and extracted with commercial extractants by adjusting the $\mathrm{pH}$ of SX feed $[29,41]$. Sn can be effectively extracted by using PC-88A diluted in EXXSOL D-80, or it can be extracted by coagulation when the optimal concentration in solution is achieved [42].

\section{Conclusions}

Selected e-waste fractions were used as feed in a specially designed pyro-electrometallurgical processing, which allowed for the generation of an electrolyte of extremely complex chemical composition and high abundance of impurities. Thus, the obtained electrolyte burden with $\mathrm{Ni}, \mathrm{Sn}, \mathrm{Fe}$, and $\mathrm{Zn}$, and 14 trace metals were used in numerous solvent extraction experiments in order to define optimal conditions for the selective $\mathrm{Cu}$ extraction-stripping process.

The results of this study showed that, under optimal conditions of 20 vol. $\%$ extractant concentration, feed $\mathrm{pH} 1.5, \mathrm{O} / \mathrm{A}$ ratio 3 , and 10 -min phase contact time, $88.1 \%$ of one stage $\mathrm{Cu}$ extraction can be achieved. Simultaneously, the co-extraction of the most abundant impurities (Ni, $\mathrm{Sn}, \mathrm{Fe}$, and $\mathrm{Zn}$ ) was under $8 \%$, and $\mathrm{Pb}$ and trace elements co-extraction was negligible. Moreover, it was determined that feed $\mathrm{pH}$ and extractant concentration influenced extraction efficiency and selectivity the most through reaction equilibrium shifts and the availability of the active chelating centers. The latter is crucial for selecting the extractant for $\mathrm{Cu}$ extraction from a chemically complex system, as can be expected in the future e-waste recycling process. Accordingly, the aldoxime reagent is optimal, with an advantage over the aldoxime/ketoxime blend. Stripping conditions, including $\mathrm{H}_{2} \mathrm{SO}_{4}$ $180 \mathrm{~g} / \mathrm{L}, \mathrm{O} / \mathrm{A}=2$, and contact time $5 \mathrm{~min}$, showed optimal efficiency from loaded organic phase containing 20 vol. \% M5640 which enabled $95.3 \%$ Cu stripping and under 6\% of the main impurities. Acid concentration and $\mathrm{O} / \mathrm{A}$ ratio predominantly influenced stripping efficiency and selectivity. Theoretical stages (McCabe Thiele diagram) for quantitative extraction and stripping were determined to be 3 and 2, respectively. Monitoring mass distribution through phases under optimal process conditions allowed the determination of positioning and quantification of each element in the system, enabling the proposal of further treatment and valorization in additional steps.

The methodology of this study and obtained results contribute to the improvement of the existing recycling processes, especially in small and medium-sized enterprises, through the development of both pyro-electro and hydrometallurgical routes capable of effectively separating and valorizing metals detained in e-waste, the valuable secondary raw material product of the increasing waste generation trend.

Author Contributions: Conceptualization, Ž.K.; methodology, Ž.K. and J.D.; formal analysis, Z.N.; data curation, J.D. and D.R.; writing — original draft preparation, J.D.; writing-review \& editing, Ž.K., D.R., and Z.A.; supervision, Ž.K. and Z.A. All authors have read and agreed to the published version of the manuscript.

Funding: This research received no external funding.

Institutional Review Board Statement: Not applicable.

Informed Consent Statement: Not applicable.

Acknowledgments: Ministry of Education, Science and Technological Development of Republic of Serbia, Contract number: 451-03-9/2021-14/200288. The expertise on the solvent extraction process provided by Cyril Bourget and Ivan Djurković is highly appreciated.

Conflicts of Interest: The authors declare no conflict of interest. 


\section{References}

1. Worell, E.; Reuter, M.A. Handbook of Recycling; Elsevier: Amsterdam, The Netherlands, 2014; ISBN 978-0-12-396459-5.

2. Dutta, D.; Panda, R.; Kumari, A.; Goel, S.; Jha, M.K. Sustainable Recycling Process for Metals Recovery from Used Printed Circuit Boards (PCBs). Sustain. Mater. Technol. 2018, 17, e00066. [CrossRef]

3. Wang, L.; Li, Q.; Sun, X.; Wang, L. Separation and Recovery of Copper from Waste Printed Circuit Boards Leach Solution Using Solvent Extraction with Acorga M5640 as Extractant. Sep. Sci. Technol. 2019, 54, 1302-1311. [CrossRef]

4. Ghosh, B.; Ghosh, M.K.; Parhi, P.; Mukherjee, P.S.; Mishra, B.K. Waste Printed Circuit Boards Recycling: An Extensive Assessment of Current Status. J. Clean. Prod. 2015, 94, 5-19. [CrossRef]

5. Forti, V.; Baldé, C.P.; Kuehr, R.; Bel, G. The Global E-Waste Monitor 2020; United Nations University (UNU)/United Nations Institute for Training and Research (UNITAR)—co-hosted SCYCLE Programme, International Telecommunication Union (ITU) \& International Solid Waste Association (ISWA): Bonn, Germany; Geneva, Switzerland; Rotterdam, The Netherlands, 2020; ISBN 978-92-808-9114-0.

6. Cayumil, R.; Khanna, R.; Rajarao, R.; Mukherjee, P.S.; Sahajwalla, V. Concentration of Precious Metals during Their Recovery from Electronic Waste. Waste Manag. 2016, 57, 121-130. [CrossRef] [PubMed]

7. Wan, X.; Fellman, J.; Jokilaakso, A.; Klemettinen, L.; Marjakoski, M. Behavior of Waste Printed Circuit Board (WPCB) Materials in the Copper Matte Smelting Process. Metals 2018, 8, 887. [CrossRef]

8. Rai, V.; Liu, D.; Xia, D.; Jayaraman, Y.; Gabriel, J.-C.P. Electrochemical Approaches for the Recovery of Metals from Electronic Waste: A Critical Review. Recycling 2021, 6, 53. [CrossRef]

9. Hagelüken, C. Recycling of Electronic Scrap at Umicore's Integrated Metals Smelter and Refinery. World Metall ERZMETALL 2006, 11, 152-161.

10. Lennartsson, A.; Engström, F.; Samuelsson, C.; Björkman, B.; Pettersson, J. Large-Scale WEEE Recycling Integrated in an Ore-Based Cu-Extraction System. J. Sustain. Metall. 2018, 4, 222-232. [CrossRef]

11. Ariizumi, M.; Takagi, M.; Inoue, O.; Oguma, N. Integrated processing of e-scrap at Naoshima smelter and refinery. In Proceedings of the Copper 2016, Kobe, Japan, 13-16 November 2016; Volume 6, p. RW 1-2.

12. Kamberović, Ž.; Ranitović, M.; Korać, M.; Jovanović, N.; Tomović, B.; Gajić, N. Pyro-Refining of Mechanically Treated Waste Printed Circuit Boards in a DC Arc-Furnace. J. Sustain. Metall. 2018, 4, 251-259. [CrossRef]

13. Forsén, O.; Aromaa, J.; Lundström, M. Primary Copper Smelter and Refinery as a Recycling Plant-A System Integrated Approach to Estimate Secondary Raw Material Tolerance. Recycling 2017, 2, 19. [CrossRef]

14. Cui, J.; Zhang, L. Metallurgical Recovery of Metals from Electronic Waste: A Review. J. Hazard. Mater. 2008, 158, 228-256. [CrossRef] [PubMed]

15. Djokić, J.; Jovančićević, B.; Brčeski, I.; Ranitović, M.; Gajić, N.; Kamberović, Ž. Leaching of Metastannic Acid from E-Waste by-Products. J. Mater. Cycles Waste Manag. 2020, 22, 1899-1912. [CrossRef]

16. Vasilyev, F.; Virolainen, S.; Sainio, T. Modeling the Liquid-Liquid Extraction Equilibrium of Iron (III) with Hydroxyoxime Extractant and Equilibrium-Based Simulation of Counter-Current Copper Extraction Circuits. Chem. Eng. Sci. 2018, 175, 267-277. [CrossRef]

17. Das, S.C.; Gopala Krishna, P. Effect of Fe(III) during Copper Electrowinning at Higher Current Density. Int. J. Miner. Process. 1996, 46, 91-105. [CrossRef]

18. Kamberović, Ž.; Ranitović, M.; Korać, M.; Andjić, Z.; Gajić, N.; Djokić, J.; Jevtić, S. Hydrometallurgical Process for Selective Metals Recovery from Waste-Printed Circuit Boards. Metals 2018, 8, 441. [CrossRef]

19. Kamberović, Ž.; Korać, M.; Ranitović, M. Hydrometallurgical process for extraction of metals from electronic waste-part II: Development of the processes for the recovery of copper from printed circuit boards (PCB). Metalurgija 2011, 17, 139-149.

20. Lister, T.E.; Wang, P.; Anderko, A. Recovery of Critical and Value Metals from Mobile Electronics Enabled by Electrochemical Processing. Hydrometallurgy 2014, 149, 228-237. [CrossRef]

21. Robinson, B.H. E-Waste: An Assessment of Global Production and Environmental Impacts. Sci. Total Environ. 2009, 408, 183-191. [CrossRef]

22. Kaya, M. Recovery of Metals and Nonmetals from Electronic Waste by Physical and Chemical Recycling Processes. Waste Manag. 2016, 57, 64-90. [CrossRef]

23. Jiang, F.; Yin, S.; Zhang, L.; Peng, J.; Ju, S.; Miller, J.D.; Wang, X. Solvent Extraction of Cu(II) from Sulfate Solutions Containing $\mathrm{Zn}(\mathrm{II})$ and $\mathrm{Fe}(\mathrm{III})$ Using an Interdigital Micromixer. Hydrometallurgy 2018, 177, 116-122. [CrossRef]

24. Tuncuk, A.; Stazi, V.; Akcil, A.; Yazici, E.Y.; Deveci, H. Aqueous Metal Recovery Techniques from E-Scrap: Hydrometallurgy in Recycling. Miner. Eng. 2012, 25, 28-37. [CrossRef]

25. Agarwal, S.; Ferreira, A.E.; Santos, S.M.C.; Reis, M.T.A.; Ismael, M.R.C.; Correia, M.J.N.; Carvalho, J.M.R. Separation and Recovery of Copper from Zinc Leach Liquor by Solvent Extraction Using Acorga M5640. Int. J. Miner. Process. 2010, 97, 85-91. [CrossRef]

26. Ochromowicz, K.; Chmielewski, T. Solvent Extraction of Copper(II) from Concentrated Leach Liquors. Physicochem. Probl. Miner. Process. 2013, 49, 357-367. [CrossRef]

27. Habashi, F. A Textbook of Hydrometallurgy; Métallurgie Extractive Québec: Sainte-Foy, QC, Canada, 1999; ISBN 978-2-9803247-7-2.

28. Jha, M.K.; Gupta, D.; Choubey, P.K.; Kumar, V.; Jeong, J.; Lee, J. Solvent Extraction of Copper, Zinc, Cadmium and Nickel from Sulfate Solution in Mixer Settler Unit (MSU). Sep. Purif. Technol. 2014, 122, 119-127. [CrossRef] 
29. Kumari, A.; Jha, M.K.; Lee, J.; Singh, R.P. Clean Process for Recovery of Metals and Recycling of Acid from the Leach Liquor of PCBs. J. Clean. Prod. 2016, 112, 4826-4834. [CrossRef]

30. Li, X.; Wei, C.; Deng, Z.; Li, C.; Fan, G.; Rong, H.; Zhang, F. Extraction and Separation of Indium and Copper from Zinc Residue Leach Liquor by Solvent Extraction. Sep. Purif. Technol. 2015, 156, 348-355. [CrossRef]

31. Deep, A.; Kumar, P.; Carvalho, J.M.R. Recovery of Copper from Zinc Leaching Liquor Using ACORGA M5640. Sep. Purif. Technol. 2010, 76, 21-25. [CrossRef]

32. Ferreira, A.E.; Agarwal, S.; Machado, R.M.; Gameiro, M.L.F.; Santos, S.M.C.; Reis, M.T.A.; Ismael, M.R.C.; Correia, M.J.N.; Carvalho, J.M.R. Extraction of Copper from Acidic Leach Solution with Acorga M5640 Using a Pulsed Sieve Plate Column. Hydrometallurgy 2010, 104, 66-75. [CrossRef]

33. Vander Linden, J. Selective Recuperation of Copper by Supported Liquid Membrane (SLM) Extraction. J. Membr. Sci. 1998, 139, 125-135. [CrossRef]

34. Kongolo, K.; Ngoie, N.; Francis, K.; Patric, T. Improving the efficiency of solvent extraction of copper by combination of hydroxyoximic extractants. In Proceedings of the International Conference on Metal Solvent Extraction 2015, Three Gorges, China, 10-14 November 2015; pp. 117-126.

35. Asghari, H.; Safarzadeh, M.S.; Asghari, G.; Moradkham, D. The Effect of Impurities on the Extraction of Copper from Sulfate Medium Using LIX®984N in Kerosene. Russ. J. Non-Ferrous Metals 2009, 50, 89-96. [CrossRef]

36. Banza, A.N.; Gock, E.; Kongolo, K. Base Metals Recovery from Copper Smelter Slag by Oxidising Leaching and Solvent Extraction. Hydrometallurgy 2002, 67, 63-69. [CrossRef]

37. Naveed, S.; Nawaz, Z. Copper Extraction from Copper Rolling Mills Scraps using Solvent "aryl aldoxime, 2-hydroxy-5nonylbenzaldoxime" (ACORGA-M5640). J. Chem. Soc. Pak. 2006, 28, 44-50.

38. De la Torre, E.; Vargas, E.; Ron, C.; Gámez, S. Europium, Yttrium, and Indium Recovery from Electronic Wastes. Metals 2018, 8 , 777. [CrossRef]

39. Wang, L.; Wang, Y.; Cui, L.; Gao, J.; Guo, Y.; Cheng, F. A Sustainable Approach for Advanced Removal of Iron from CFA Sulfuric Acid Leach Liquor by Solvent Extraction with P507. Sep. Purif. Technol. 2020, 251, 117371. [CrossRef]

40. Ocaña, N.; Alguacil, F.J. Solvent Extraction of Iron(III) by MOC-55 TD: Experimental Equilibrium Study and Demonstration of Lack of Influence on Copper(II) Extraction from Sulphate Solutions. Hydrometallurgy 1998, 48, 239-249. [CrossRef]

41. Sridhar, V.; Verma, J.K. Recovery of Copper, Nickel and Zinc from Sulfate Solutions by Solvent Extraction Using LIX 984 N. E-J. Chem. 2011, 8, S434-S438. [CrossRef]

42. Inoue, K.; Mirvaliev, R.; Yoshizuka, K.; Ohto, K.; Babasaki, S.-Y. Solvent extraction of TIN(IV) with PC-88A from sulfuric acid solutions containing chloride ions. Solvent. Extr. Res. Dev. Jpn. 2001, 8, 21-25. 